Q

Check for

updates

Cite as

Nano-Micro Lett.

(2020) 12:91

Received: 3 February 2020

Accepted: 25 March 2020

Published online: 13 April 2020

(C) The Author(s) 2020

\section{Improved Photoresponse of UV Photodetectors by the Incorporation of Plasmonic Nanoparticles on GaN Through the Resonant Coupling of Localized Surface Plasmon Resonance}

\author{
Sundar Kunwar ${ }^{1}$, Sanchaya Pandit ${ }^{1}$, Jae-Hun Jeong ${ }^{1}$, Jihoon Lee ${ }^{1 凶}$ \\ $\triangle$ Jihoon Lee, jihoonlee@kw.ac.kr \\ 1 Department of Electronic Engineering, College of Electronics and Information, Kwangwoon University, \\ Nowon-gu, Seoul 01897, South Korea
}

\title{
HIGHLIGHTS
}

- Enhancement of UV photoresponse by the incorporation of various plasmonic nanoparticles in the detector architecture.

- Detailed explanation for the photocurrent enhancement mechanism by the finite-difference time domain (FDTD) simulation and strong plasmon absorption.

- Systematic comparison and demonstration of the superior photoresponse of homogeneously alloyed AgAu nanoparticles as compared to the monometallic nanoparticles.

\begin{abstract}
Very small metallic nanostructures, i.e., plasmonic nanoparticles (NPs), can demonstrate the localized surface plasmon resonance (LSPR) effect, a characteristic of the strong light absorption, scattering and localized electromagnetic field via the collective oscillation of surface electrons upon on the excitation by the incident photons. The LSPR of plasmonic NPs can significantly improve the photoresponse of the photodetectors. In this work, significantly enhanced photoresponse of UV photodetectors is demonstrated by the incorporation of various plasmonic NPs in the detector architecture. Various size and elemental composition of monometallic Ag and Au NPs, as well as bimetallic alloy AgAu NPs, are fabricated on $\mathrm{GaN}$ (0001) by the solid-state dewetting approach. The photoresponse of various NPs are tailored based on the geometric and elemental evolution of NPs, resulting in the highly enhanced photoresponsivity of $112 \mathrm{~A} \mathrm{~W}^{-1}$, detectivity of $2.4 \times 10^{12}$ Jones and external

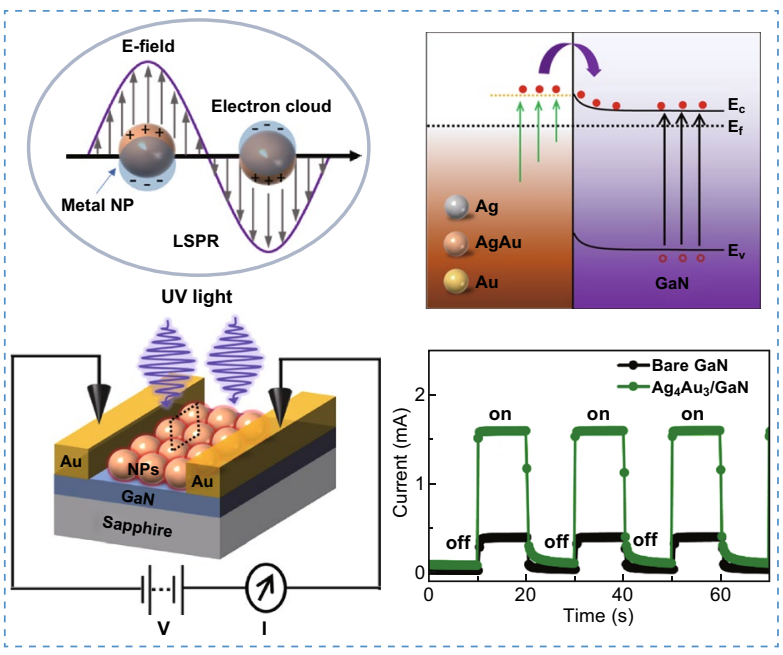
quantum efficiency of $3.6 \times 10^{4} \%$ with the high Ag percentage of AgAu alloy NPs at a low bias of $0.1 \mathrm{~V}$. The AgAu alloy NP detector also demonstrates a fast photoresponse with the relatively short rise and fall time of less than 160 and 630 ms, respectively. The improved photoresponse with the AgAu alloy NPs is correlated with the simultaneous effect of strong plasmon absorption and scattering, increased injection of hot electrons into the GaN conduction band and reduced barrier height at the alloy NPs/GaN interface.
\end{abstract}

KEYWORDS UV photodetection; NP-based photodetectors; Nanoparticles; Plasmonic enhancement 


\section{Introduction}

In recent years, ultraviolet (UV) detection has gained tremendous research attentions inspired by a wide range of applications in optoelectronics, environmental and biological monitoring, industrial automation, flame sensing, military communication, and space exploration [1-10]. The UV photodetectors feature the high sensitivity, fast response, low power consumption, and stable operation and thus can be utilized in the various aforementioned applications [11-13]. As an example, the UV communication system has been successfully developed for the unattended ground sensor networks, owing to the less interference from the visible light and insensitivity to the meteorological conditions and scatterings [10]. At the same time, the plasmonic nanomaterials that induce the localized surface plasmon resonances (LSPR) due to the collective oscillation of conduction band electrons have been gaining considerable research attention as the promising candidates to achieve the improved performance of various photodetectors [6, 14]. For example, the $\mathrm{Cu}$ nanostructure/ $\mathrm{ZnO}$ quantum dots hybrid architecture exhibited the ultrahigh UV photoresponsivity due to the enhanced plasmon scattering by the $\mathrm{Cu}$ nanostructures in the $\mathrm{ZnO}$ photoactive layer [15]. To date, various UV photodetectors have been demonstrated by the modification of nanoscale surface properties of photoactive materials, i.e., wide bandgap semiconductors of $\mathrm{GaN}, \mathrm{ZnO}, \mathrm{TiO}_{2}$, and $\mathrm{SiC}$, as well as by the integration of advanced nanomaterials such as metallic nanoparticles (NPs), two-dimensional materials, and quantum dots [16-20]. For instance, the fabrication of heterostructures nanowires of semiconductors such as bicrystalline $\mathrm{GaN}$, Al-doped $\mathrm{ZnO} / \mathrm{ZnO}$ nanorings/PVK/PEDOT:PSS and crystalline silicon/porous silicon have been realized for high UV photoresponsivity and fast response speed [21-23]. In addition, the theoretical study of UV photodetector parameters such as active area, structure composition, and electrode materials could allow one to design a high-performance optoelectronic devices [24, 25]. Among various semiconductors, $\mathrm{GaN}$ has become a promising candidate for the UV detection due to its wide $(\sim 3.4 \mathrm{eV})$ direct bandgap, high carrier mobility, excellent chemical and thermal stability, and high electrical break down voltage [23]. In order to achieve the high responsivity, high quantum efficiency and faster response GaN-based UV photodetectors, the synthesis of nanostructured $\mathrm{GaN}$ layer, nanowires and integration of plasmonic metal NPs have been demonstrated $[14,17,26]$. However, the detailed study on the application of plasmonic AgAu alloy NPs in the UV photodetectors has not been attempted up to now. The Ag and Au NPs have shown excellent optical absorption, scattering, electromagnetic near-field, and charge transfer characteristics due to their strong LSPR effect in the UV-Vis regions [27-29]. Generally, the LSPR of Ag NPs is in the shorter wavelength $(<430 \mathrm{~nm})$ as compared to the Au NPs (>530 nm). Due to the synergistic effect of the $\mathrm{Ag}$ and $\mathrm{Au}$, the $\mathrm{AgAu}$ alloy NPs can offer several advantages, i.e., a broader LSPR band, increased charge carrier density, longer carrier lifetime, and stability against oxide formation. On the other hand, the interfacial properties between plasmonic NPs and GaN such as Schottky barrier height can inherently be modified by the elemental composition of $\mathrm{AgAu}$, which can be exploited to improve the excited carrier transfer between the plasmonic NPs and GaN. Thus, the composite alloy AgAu NPs can further boost the photoresponsivity, stability, and sensitivity of UV photodetectors for various practical optoelectronic devices.

In this work, the significantly improved photoresponse of UV photodetectors by the incorporation of plasmonic NPs on $\mathrm{GaN}$ has been systematically demonstrated by the control of size and elemental composition as shown in Fig. 1. The maximum UV photoresponse is demonstrated with the higher Ag composition of AgAu alloy NPs, which exhibits a high responsivity of $112 \mathrm{~A} \mathrm{~W}^{-1}$, detectivity of $2.4 \times 10^{12}$ Jones, and external quantum efficiency $(E Q E)$ of $3.6 \times 10^{4} \%$ under UV illumination of $0.03 \mathrm{~mW} \mathrm{~mm}^{-2}$ at $0.1 \mathrm{~V}$. The fully alloyed $\mathrm{AgAu}$ NPs and pure Ag and Au NPs are fabricated by the solid-state dewetting approach, which takes the advantages of atomic diffusion, interdiffusion and agglomeration upon annealing to form the definite shape and size of NPs. Depending upon the morphological and elemental evolution of the NPs, the photoresponse of corresponding device is dynamically varied due to the drastic variation in the LSPR response. Compared to the monometallic Ag and Au NPs, the alloy NPs exhibit high photoresponsivity, detectivity, and $E Q E$ due to the enhanced light absorption, scattering, hot electron excitation, and reduced barrier height at the GaN interface, which is correspondingly discussed along with the electromagnetic field simulation and energy band theory. Furthermore, the NPs based UV photodetectors also demonstrate an excellent photoresponse characteristic under zero bias (self-driven mode). 
(a)

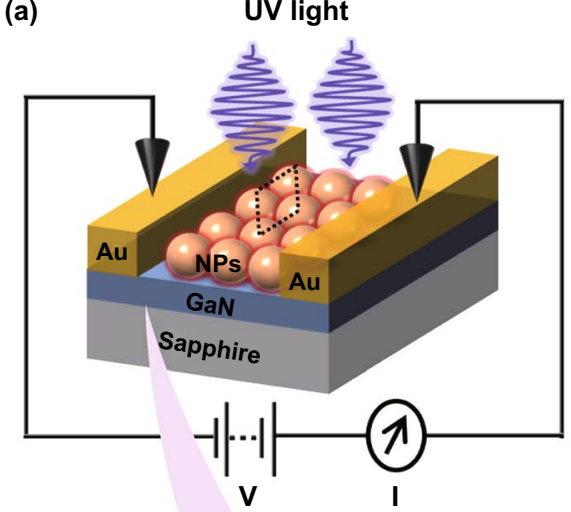

(b)

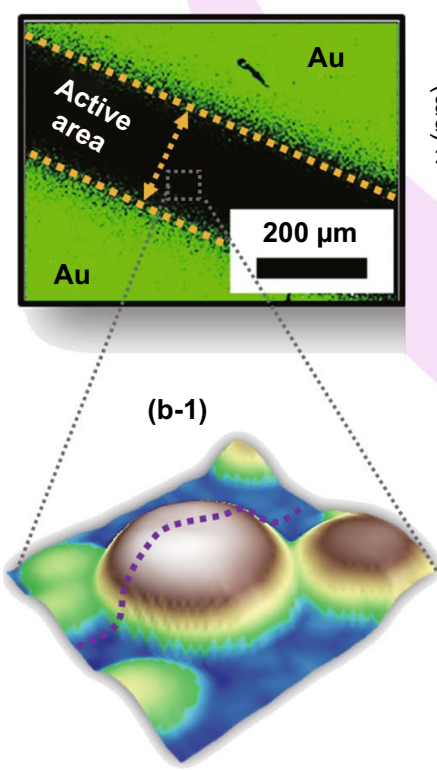

Fig. 1 a Schematic of plasmonic metallic NPs based UV photodetector on GaN. b EDS elemental map of the photodetector active region and Au electrode. (b-1) AFM surface morphology of typical metallic NPs in the active region. $\mathbf{c}$ EDS spectra of NPs in the active region. $\mathbf{d}$ E-field distribution of typical metallic NP by finite-difference time domain (FDTD) simulation. e Schematic of localized surface plasmon resonance (LSPR) induced on the metal NPs by incident light. f Photoresponse of the bare $\mathrm{GaN}$ and $\mathrm{Ag}_{4} \mathrm{Au}_{3}$ at $0.1 \mathrm{~V}$ bias upon illumination of UV $(385 \mathrm{~nm})$ light

\section{Experimental Section}

\subsection{Sample Preparation}

In this study, various mono- and bimetallic NPs were fabricated on the epitaxially grown c-plane $\mathrm{GaN}$ (0001) template on sapphire (PAM-XIAMEN, China) and the samples were adapted for the fabrication of UV photodetectors. The GaN template was $\sim 5 \mu \mathrm{m}$ thick n-type with the resistivity $<0.5 \mathrm{ohms}$-cm and a dislocation density of $<1 \times 10^{8} \mathrm{~cm}^{-2}$. Firstly, the large wafer was cleaved into $6 \times 6 \mathrm{~mm}^{2}$ square pieces by a mechanical saw. Then, the substrates were subjected to a degassing process in (d)
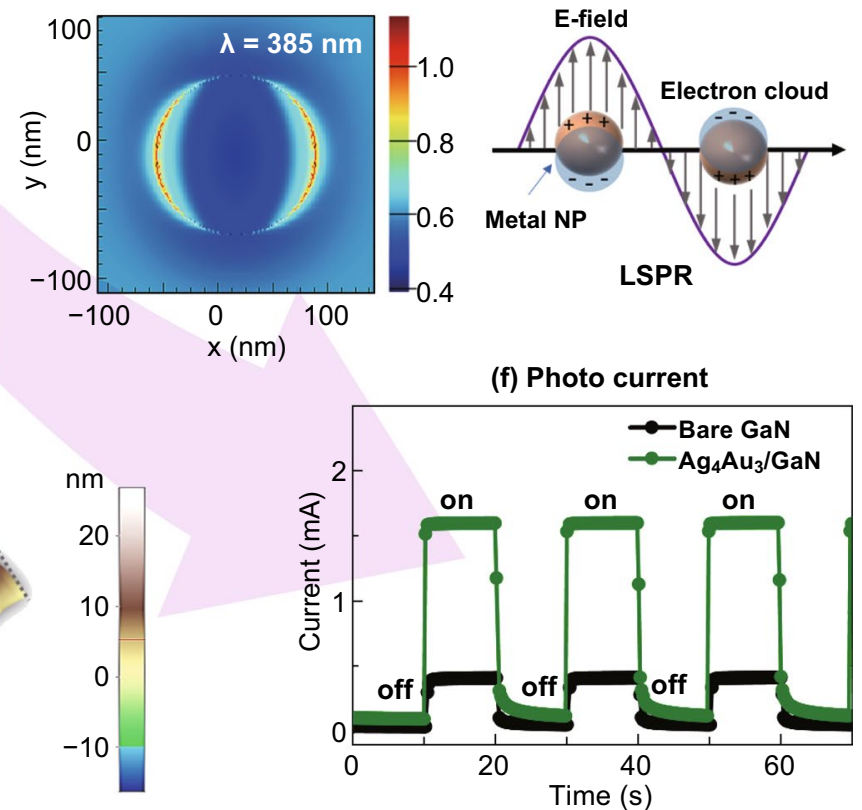

(e)

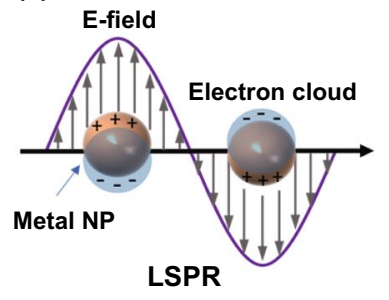

LSPR

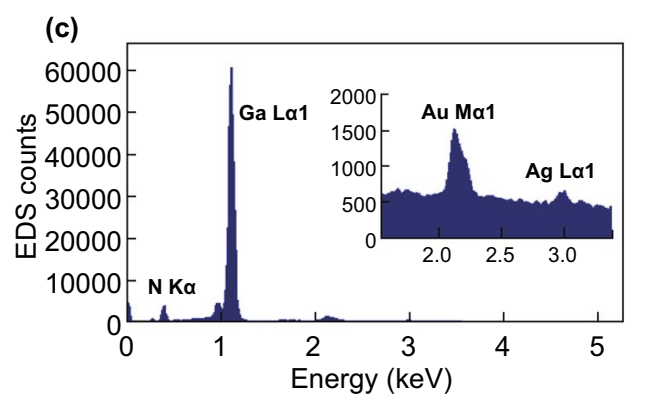


substrate. The deposition of metallic films was performed in a sputtering chamber under $1 \times 10^{-1}$ torr at the deposition rate of $0.05 \mathrm{~nm} \mathrm{~s}^{-1}$ (20 s equals to $1 \mathrm{~nm}$ ) and ionization current of $3 \mathrm{~mA}$. First, the thin films of $\mathrm{Ag}(8$ and $15 \mathrm{~nm})$ and $\mathrm{Au}(3$ and $5 \mathrm{~nm}$ ) were deposited to fabricate pure $\mathrm{Ag}$ and $\mathrm{Au}$ NPs of different size on GaN. Second, two series of $\mathrm{Ag}_{\mathrm{x}} \mathrm{Au}_{\mathrm{y}}$ ( $\mathrm{x}$ and $\mathrm{y}$ are the corresponding layer thickness) bilayers with a total thickness of $5\left(\mathrm{Ag}_{3} \mathrm{Au}_{2}, \mathrm{Ag}_{2.5} \mathrm{Au}_{2.5}, \mathrm{Ag}_{2} \mathrm{Au}_{3}\right)$ and $7 \mathrm{~nm}\left(\mathrm{Ag}_{4} \mathrm{Au}_{3}, \mathrm{Ag}_{3.5} \mathrm{Au}_{3.5}, \mathrm{Ag}_{3} \mathrm{Au}_{4}\right)$ were deposited to fabricate $\mathrm{AgAu}$ alloy NPs with different size and elemental composition. For the fabrication of NPs, the $\mathrm{Ag}$ and $\mathrm{AgAu}$ bilayer films were annealed at $500{ }^{\circ} \mathrm{C}$ while the Au films were annealed at $650{ }^{\circ} \mathrm{C}$. For the fabrication of UV photodetectors, the Au electrodes were deposited on each NP sample and bare $\mathrm{GaN}$ as a reference as shown in Fig. 1a, b. A shadow mask of a $200-\mu$ m gap was placed on samples and then 100-nm-thick Au electrodes were deposited by sputtering. The photodetector devices were named according to the sample characteristics such as bare $\mathrm{GaN}, \mathrm{Ag}, \mathrm{Au}$, and $\mathrm{Ag}_{\mathrm{x}} \mathrm{Au}_{\mathrm{y}}$.

\subsection{Characterizations and Simulation}

The surface morphology of as-fabricated NPs was studied by a non-contact mode atomic force microscope (NC-AFM) (XE-70, Park Systems Corp. South Korea) and scanning electron microscope (SEM) (Regulus 8230, Hitachi, Japan). For the elemental characterizations of samples, energydispersive X-ray spectroscopes (EDS) (Noran System 7, Thermo Fisher, United States and Ultimax, Oxford Instruments, United Kingdom) were utilized. Optical characterization was performed by using a NOST system (Nostoptiks, South Korea), equipped with an ANDOR sr-500i spectrograph, CCD detector and combined deuterium-halogen light source (Ocean Optics, United Kingdom). Besides, the electromagnetic (EM) field and optical spectra of typical NPs on $\mathrm{GaN}$ were simulated by using a finite-difference time domain (FDTD) software (Lumerical Solutions, Canada). A plane wave source from 250 to $1100 \mathrm{~nm}$ in wavelength was used to excite the NPs on GaN from the $z$-direction. The perfectly matched layer (PML) boundary condition was applied in $z$-direction and the periodic boundary was applied in $x$, $y$-direction. The distance between the PML and the NP was half of the maximum wavelength to avoid interference. For the simulation, an auto-shut-off level of $10^{-6}$ and a 3D mesh grid of $0.5 \mathrm{~nm}$ were used. The complex refractive index of $\mathrm{Au}, \mathrm{Ag}$, and $\mathrm{AgAu}$ alloy was taken from the Rioux's model [30]. Similarly, Kawashima's model was referenced for the refractive index of GaN [31]. The photocurrent measurement of various devices was taken by using the B2902A precision source/measure unit (Keysight Technologies, USA). The high-power light-emitting diode (LED) of UV and VIS wavelengths (Mightex, Canada) was utilized to excite the photodetectors with the focus and collimator lenses with $10 \mathrm{~mm}$ focal length. The LED power was measured by a power meter (XLP12-3S-H2-D0, Genetec-eo, Canada). All the optical and photocurrent measurements were taken under dark and illumination at an ambient temperature.

\section{Results and Discussion}

\subsection{Monometallic Ag/Au NPs and Growth Mechanism}

Figure 2 shows the morphological and optical properties of the bare $\mathrm{GaN}$, monometallic $\mathrm{Ag}$, and $\mathrm{Au}$ samples. The surface morphology of each sample is demonstrated by the 3D-AFM side-views and the large-scale AFM top-views are provided in Fig. S2. In addition, the dimensions of the $\mathrm{Ag}$ and Au NPs are studied by the RMS roughness $\left(R_{\mathrm{q}}\right)$, surface area ratio $(S A R)$, and average diameter distribution histograms. As shown in Fig. 2a, the surface of bare GaN showed the smooth atomic ripples on the surface after degassing. With the deposition of thin metallic films on GaN and subsequent annealing, the well-developed and isolated $\mathrm{Ag}$ and $\mathrm{Au}$ NPs were obtained owing to the solid-state dewetting well below the melting point of each metallic element $[32,33]$. Specifically, the deposited metallic atoms can undergo sufficient thermal energy-driven surface diffusion and agglomerate in order to reduce the surface and interface energies [34]. The diffusivity $\left(D_{s}\right)$ of atoms directly depends upon the temperature of the system as below as Eq. 1 [35]:

$D_{s} \propto e^{-E_{a} / k T}$

where the $E_{a}$ is the activation energy of metal, $k$ is the Boltzmann constant, and $T$ is the annealing temperature. Besides, the evolution of NPs can be affected by the intrinsic properties of different metals, initial thickness, and annealing duration. Thus, the initial thickness and growth conditions for $\mathrm{Ag}$ and $\mathrm{Au}$ films were chosen to achieve the similar size and density of Ag and Au NPs. In specific, the initial thickness 
(a) $\mathrm{GaN}$

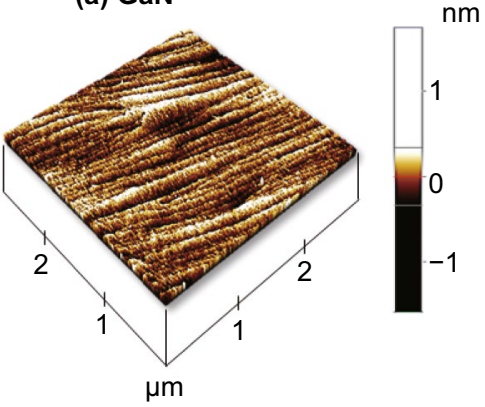

(d)

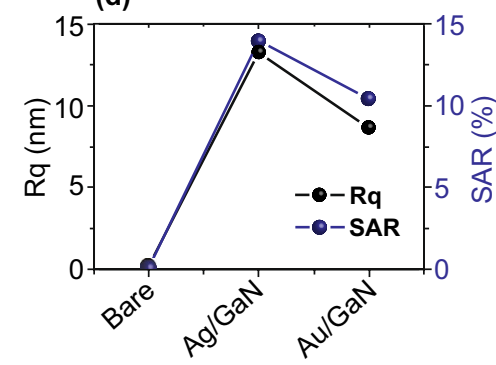

(e) Bare GaN

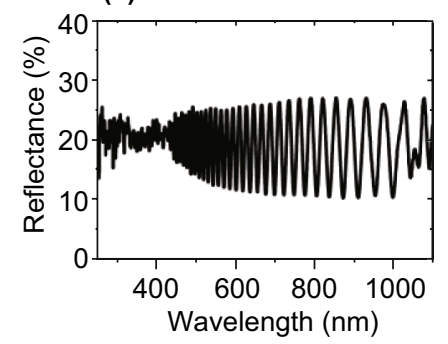

(b) $\mathrm{Ag} / \mathrm{GaN}$

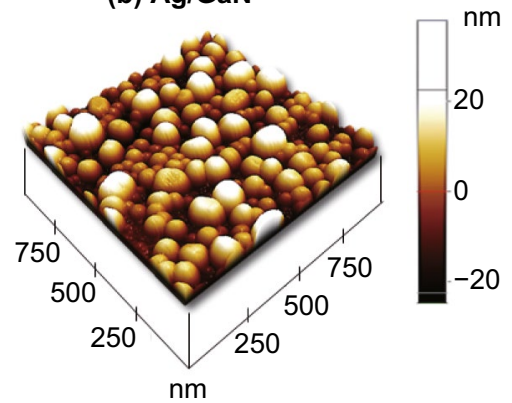

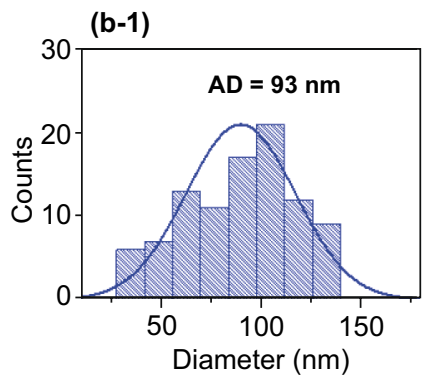

(c) Au/GaN
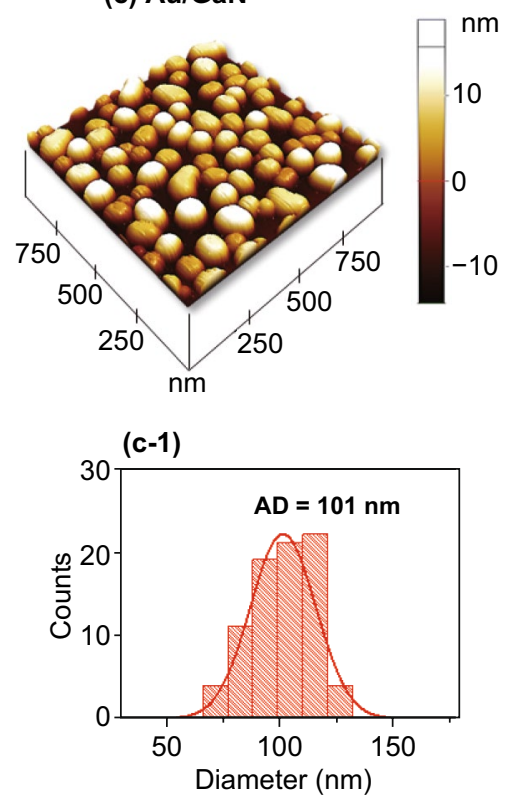

(g) $\mathrm{Au} / \mathrm{GaN}$
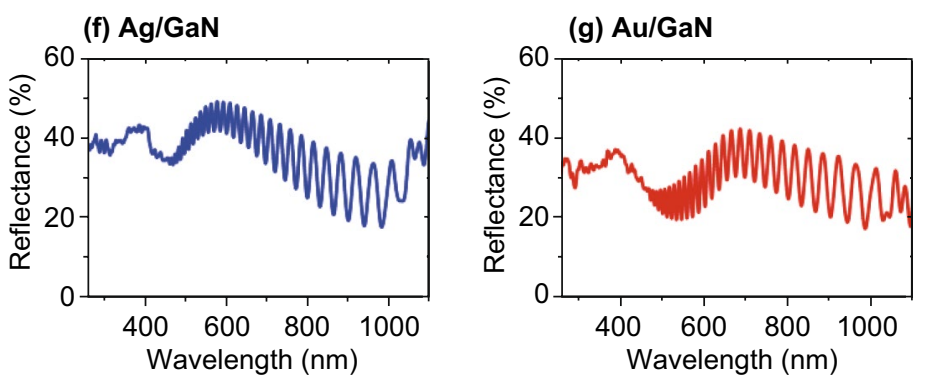

Fig. 2 Morphological and optical analysis of bare GaN, Ag, and Au samples. a-c AFM side-views of the corresponding samples. b-1, c-1 Diameter distribution histograms of the Ag and Au NPs on GaN. d Summary plots of Rq and SAR. e-g Reflectance spectra of bare GaN, Ag, and Au samples in the UV-VIS-NIR region

of $\mathrm{Ag}$ and $\mathrm{Au}$ was 15 and $5 \mathrm{~nm}$ for which the applied annealing conditions were $500{ }^{\circ} \mathrm{C}$ for $180 \mathrm{~s}$ and $650{ }^{\circ} \mathrm{C}$ for $450 \mathrm{~s}$, respectively. After annealing at specified temperatures and duration under vacuum, the isolated and evenly distributed $\mathrm{Ag}$ and $\mathrm{Au}$ NPs were formed as displayed in Fig. 2b, c. The average diameter of Ag and Au NPs was found to be $\sim 93$ and $101 \mathrm{~nm}$, respectively, as shown in Figs. $2 \mathrm{~b}-1$ and c-1. In addition, the $R q$ and $S A R$ were also extracted from the AFM images and summarized in Fig. 2d. Since the bare $\mathrm{GaN}$ was smooth and flat, the $R_{\mathrm{q}}$ and $S A R$ were less than $2 \mathrm{~nm}$ and $0.009 \%$, respectively. With the fabrication of semi-spherical $\mathrm{Ag}$ and $\mathrm{Au}$ NPs, the $R_{\mathrm{q}}$ increased to 13.23 and $8.23 \mathrm{~nm}$ while the $S A R$ to 13.9 and $10.4 \%$, respectively. Furthermore, the optical properties of bare $\mathrm{GaN}, \mathrm{Ag}$, and $\mathrm{Au}$ samples were studied by the reflectance spectra in the UV-VIS-NIR regions $(250-1100 \mathrm{~nm})$. The bare $\mathrm{GaN}$ exhibited a flatter reflectance spectrum with the characteristic reflectance ripples as shown in Fig. 2e with an average reflectance of $19 \%$. The strong ripples in the reflectance can be attributed by the interference between the reflected photons from the air/GaN and GaN/Sapphire interfaces as shown in Fig. S1f. In the case of NP samples, the average reflectance was largely increased due to the high reflectivity of $\mathrm{Ag}$ and $\mathrm{Au}$ as witnessed in Fig. 2f, g [36]. Meanwhile, the reflectance spectra of the NPs samples revealed the wavelength dependency in the UV and VIS regions likely due to the LSPR effect of the $\mathrm{Au}$ and Ag NPs [37]. In specific, the reflectance dip for Ag NPs was at $\sim 450 \mathrm{~nm}$, which was shorter than that for the $\mathrm{Au}$ NPs at $540 \mathrm{~nm}$. Generally, the reflectance dips and peaks of Au NPs were red-shifted as compared to the Ag NPs as the LSPR of Au NPs occur at longer wavelength [38]. The UV and VIS reflectance dips can be correlated with the excitation of dipolar and quadrupolar or higher-order resonance modes on the NPs by incident photons [39]. 


\subsection{UV Photoresponse of Monometallic Ag and Au NPs}

Figure 3 presents the photoresponse of the bare $\mathrm{GaN}, \mathrm{Ag}$, and $\mathrm{Au}$ UV photodetectors excited by a power tunable UVLED of $385 \mathrm{~nm}$ peak wavelength. A complete layout of the UV photodetectors is presented in Figs. 1a and S2a, describing the device architecture, active region, and light illumination scheme. For the measurement of linear current-voltage $(I-V)$, the voltage range was varied between $\pm 0.1 \mathrm{~V}$ with the fixed power of $10.36 \mathrm{~mW} \mathrm{~mm}^{-2}$, illuminated on the active area of devices. The dark- and photocurrent of devices with and without NPs demonstrated significant differences as shown in Fig. 3a. Under dark, all three devices showed linearly increasing current in the order of $10^{-6}$ (bare $\mathrm{GaN}$ ) to $10^{-5} \mathrm{~A}(\mathrm{NPs} / \mathrm{GaN})$ at $0.1 \mathrm{~V}$ as shown in the inset of Fig. 3a, which indicates the quasi-Ohmic nature of devices [40]. It was observed that the dark current of $\mathrm{Au}$ and $\mathrm{Ag}$ devices was successively enhanced than the bare $\mathrm{GaN}$, which could be mainly due to the thermionic emission and tunneling current [24]. At the same time, as the Schottky barrier height of $\mathrm{Ag} / \mathrm{GaN}$ can be smaller than that of $\mathrm{Au} / \mathrm{GaN}$ due to the lower work function, the dark current can increase further due to the increased thermionic emission of carriers [26]. The symmetrical characteristic of the $I-V$ curve also indicates similar built-in electric field at the Au electrode/GaN junction and minimal surface state at the NPs/GaN interfaces [26, 41]. With the UV illumination, the photocurrent of bare, Ag and Au was sharply increased throughout the voltage range. For the detailed understanding of photoresponse behaviors, the pulsed UV light was illuminated at fixed $0.1 \mathrm{~V}$ as shown in Fig. 3b. Under an identical condition of applied voltage and photon power, the photocurrent of $\mathrm{Ag}$ and $\mathrm{Au}$ was found to be increased by $\sim 2.8$ and $~ 4.6$ times, respectively, as compared to the bare as clearly seen in Fig. 3b. In specific, the photocurrent of bare $\mathrm{GaN}, \mathrm{Ag}$, and Au reached up to $3.56 \times 10^{-4}, 9.97 \times 10^{-4}$, and $1.61 \times 10^{-3} \mathrm{~A}$, respectively, at $0.1 \mathrm{~V}$ and $10.36 \mathrm{~mW} \mathrm{~mm}^{-2}$. The integration of $\mathrm{Ag}$ and $\mathrm{Au}$ NPs on the bare GaN photodetector demonstrated a strong contribution toward photocurrent enhancement due to the LSPR effect $[29,42]$. At the same time, it was also observed that the Au NPs induced much larger photocurrent as compared to the Ag NPs, which suggests the morphological and elemental dependence of LSPR in the photocurrent enhancement. Furthermore, the photon powerdependent photoresponse of each device was evaluated at fixed bias as shown in Fig. 3c-e. All three devices exhibited a consistent increment in the photocurrent with the power

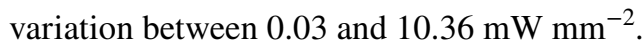

The device performance was further evaluated by determining the figure of merit parameters for photodetectors such as, responsivity $(R)$, specific detectivity $(D)$ and external quantum efficiency $(E Q E)$ at various power. The $R$ is defined as the ratio of photocurrent generated to illuminated optical power intensity and expressed as Eq. 2 [29]:

$R=\frac{I_{p h}-I_{d}}{P_{d} \times A}$

where $I_{p h}$ is the photocurrent, $I_{d}$ is the dark current, $P_{d}$ is the power density (in $\mathrm{mW} \mathrm{mm}^{-2}$ ) and $A$ is the active area (in $\mathrm{mm}^{2}$ ) of device. According to the equation above the $R$ was calculated at different optical power and plotted in Fig. 3f. In general, $R$ was maximum at lower power, i.e., $0.03 \mathrm{~mW} \mathrm{~mm}^{-2}$ and was exponentially decreased at increased power, which could be attributed to the saturation of trap state in the GaN film for further injection of carriers [12]. The $\mathrm{R}$ was much enhanced with the incorporation of $\mathrm{Ag}$ and $\mathrm{Au} \mathrm{NPs.} \mathrm{For} \mathrm{example,} \mathrm{the} \mathrm{bare} \mathrm{GaN}$ showed 7.26 $\mathrm{A} \mathrm{W}^{-1}$ while $\mathrm{Ag}$ and $\mathrm{Au} \mathrm{NP}$ detectors showed 58.5 and $97.4 \mathrm{~A} \mathrm{~W}^{-1}$ at $0.03 \mathrm{~mW} \mathrm{~mm}^{-2}$. Furthermore, another parameter detectivity $(D)$ denotes the photodetector sensitivity and calculated as Eq. 3:

$D=R \cdot A^{1 / 2} /\left(2 e I_{d}\right)^{1 / 2}$

where, $R$ is the calculated responsivity, $A$ is the active area, $e$ is the elementary charge and $I_{d}$ is the dark current. From the calculation of $D$, it was also found to be significantly increased with the integration of Ag and Au NPs in the photodetectors as displayed in Fig. 3g. The Au photodetector exhibited a high value of $1.94 \times 10^{12}$ Jones at the $P_{d}$ of 0.03 $\mathrm{mW} \mathrm{mm}{ }^{-2}$, which is 1.98 and 6.67 times higher than $\mathrm{Ag}$ and bare $\mathrm{GaN}$ photodetectors respectively. In addition, the external quantum efficiency $(E Q E)$ that determines the ratio of photocurrent to the incident photon flux was determined as Eq. 4 [15]:

$E Q E=R \times \frac{1240}{\lambda} \times 100 \%$

where $\lambda$ is the excitation wavelength ( $385 \mathrm{~nm}$ ). Similarly, the $E Q E$ of bare $\mathrm{GaN}, \mathrm{Ag}$, and Au photodetectors were maximum at $0.03 \mathrm{~mW} \mathrm{~mm} \mathrm{~m}^{-2}$ and then gradually decreased with the increased power as shown in Fig. 3h. The EQE of Au detector was $3.13 \times 10^{4}$, which was $\sim 1.67$ and 13.4 times higher than the $\mathrm{Ag}$ and bare $\mathrm{GaN}$ devices with the $E Q E$ of $1.88 \times 10^{4}$ and $2.33 \times 10^{3}$. The specific values of $R, D$, and $E Q E$ are summarized at each power density in Table S2. 
(a) Photo Current

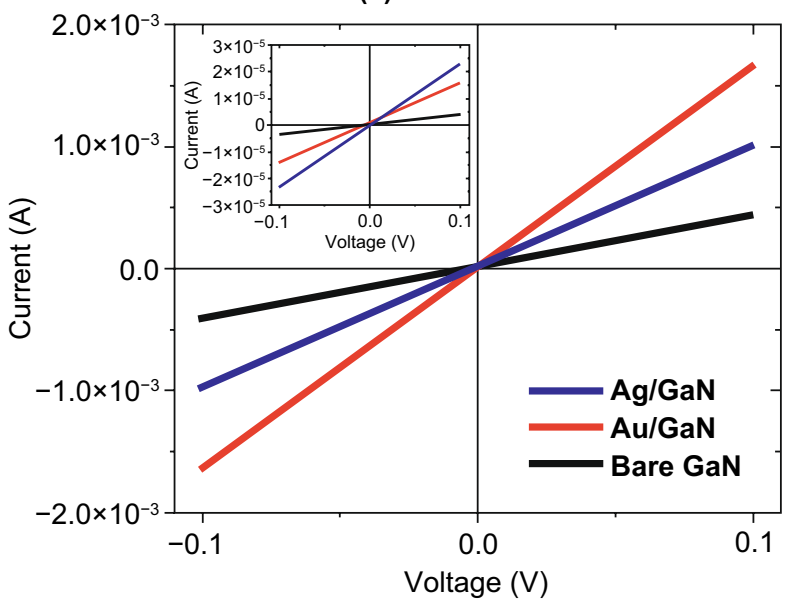

(c) Bare GaN

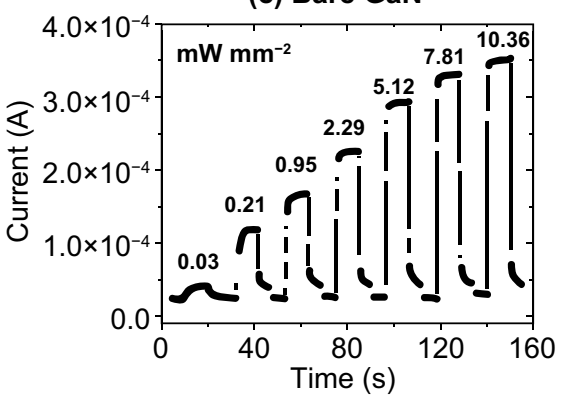

(f) Responsivity

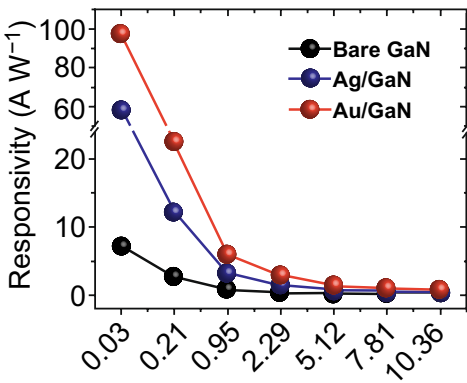

Power $\left(\mathrm{mW} \mathrm{mm}^{-2}\right)$

(i) $\mathrm{Ag} / \mathrm{GaN}$

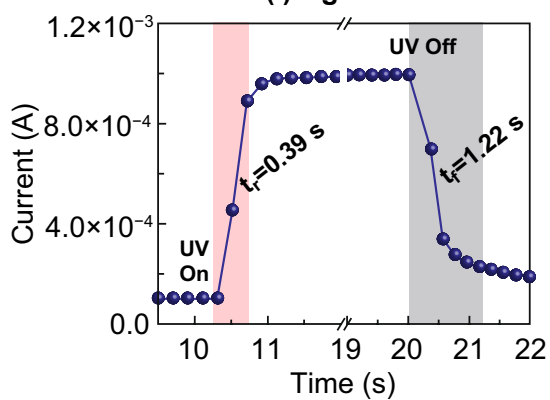

(b) Photo Current

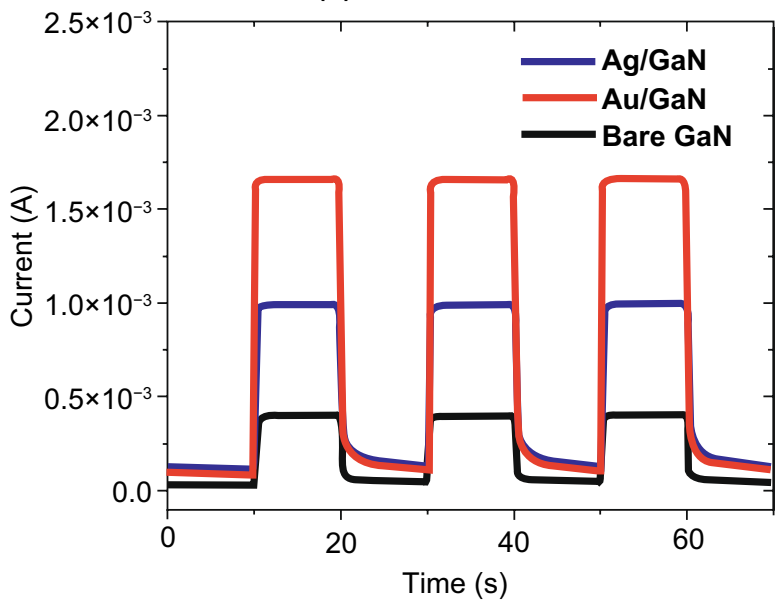

(e) Au/GaN (d) $\mathrm{Ag} / \mathrm{GaN}$

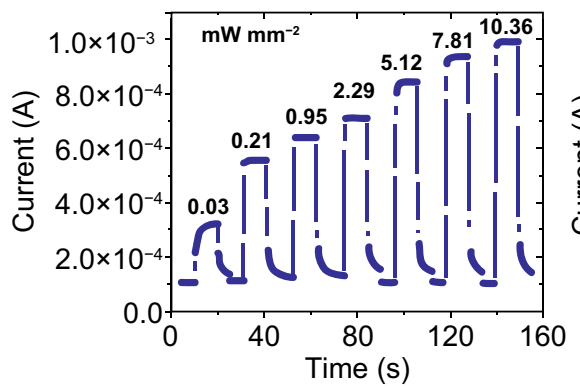

(g) Detectivity

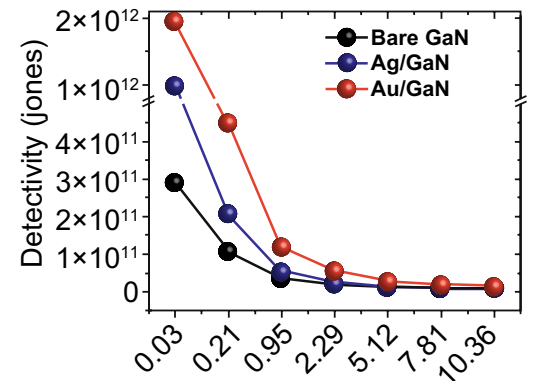

Power $\left(\mathrm{mW} \mathrm{mm}^{-2}\right)$

(j) $\mathrm{Au} / \mathrm{GaN}$

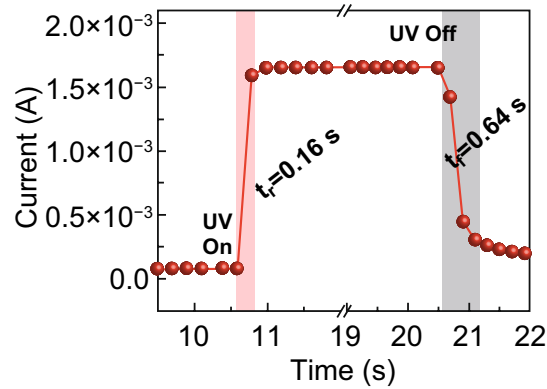

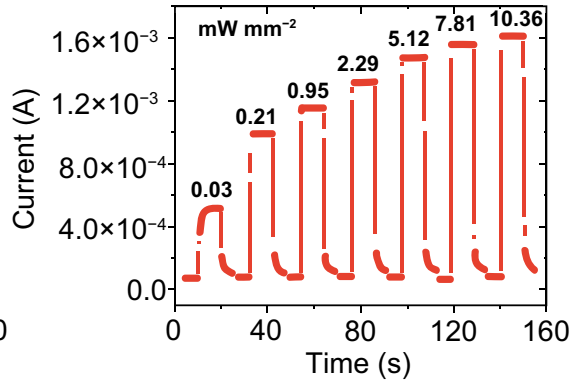

(h) EQE

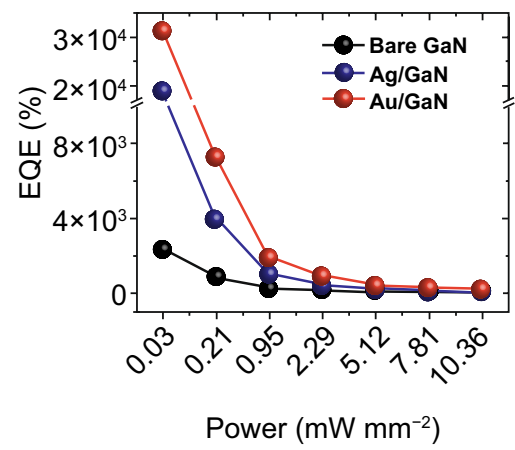

(k) At 0 bias

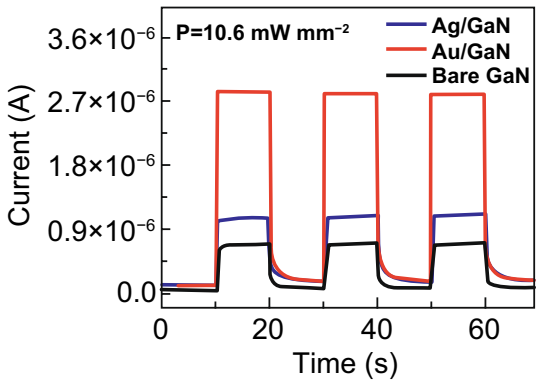

Fig. 3 Photoresponse characteristics of the bare GaN, Ag and Au photodetectors. a Current-voltage (I-V) characteristics of each device under $385 \mathrm{~nm}$ UV illumination at $10.36 \mathrm{~mW} \mathrm{~mm}^{-2}$. Inset shows the corresponding dark current. b Current-time $(I-t)$ characteristic at $0.1 \mathrm{~V}$ by switching on/off. $\mathbf{c}-\mathbf{e}$ Photon power-dependent photoresponse of the devices. f-h Summary of the photoresponsivity $(R)$, detectivity $(D)$ and external quantum efficiency $(E Q E)$ as a function of photon power. $\mathbf{i}-\mathbf{j}$ Rise $\left(t_{r}\right)$ and fall $\left(t_{f}\right)$ time of the $\mathrm{Ag}$ and Au detectors upon switching on/off. $\mathbf{k}$ Current-time $(I-t)$ characteristic at 0 bias under $10.36 \mathrm{~mW} \mathrm{~mm}^{-2} \mathrm{UV}$ illumination 
The response of the $\mathrm{Ag}$ and $\mathrm{Au}$ photodetectors was evaluated by the rise and fall time of photocurrent upon on-off switching as shown in Fig. 3i, j. Here, the rise time $\left(t_{r}\right)$ and fall time $\left(t_{f}\right)$ denote the time required to reach $90 \%$ of maximum photocurrent with the increase and the $10 \%$ of dark current while decreasing, respectively. The $\mathrm{Au}$ device demonstrated a shorter response time, i.e., $t_{r}$ : $0.16 \mathrm{~s}$ and $t_{f}: 0.64 \mathrm{~s}$ while the $\mathrm{Ag}$ detector showed 0.39 and $1.22 \mathrm{~s}$, respectively. This can be due to the longer hot carrier lifetime of Ag NPs on the Fermi surface as compared with the Au NPs [43]. Figure 3k shows the photoresponse of devices under the illumination UV $\left(10.36 \mathrm{~mW} \mathrm{~mm}^{-2}\right)$ at zero bias. As all the devices fabricated in this work exhibited a non-zero dark current as shown in Fig. S2d likely due to the thermionic, thermionic-field emission, and minor built-in potential variation at the $\mathrm{Au} / \mathrm{GaN}$ electrodes, they can be operated at zero bias [40]. A continuous three UV on-off cycles show the sharp rise and decay of photocurrent, suggesting the highly responsive self-driven UV photodetector operation [9, 23, 27]. The photoresponse of smaller $\mathrm{Ag}$ and $\mathrm{Au}$ NPs showed a similar trend with the relatively lower photocurrents as presented in Figs. S4 and S5.

\subsection{Characterization of Bimetallic AgAu Alloy NPs}

Figure 4 shows the fabrication of alloy NP photodetectors with the various $\mathrm{Ag}$ and $\mathrm{Au}$ compositions. To further explore the synergistic behavior of alloy NP UV photodetectors, the $\mathrm{AgAu}$ alloy NPs were fabricated with the Ag/Au bilayers on $\mathrm{GaN}$. For the fabrication of AgAu alloy NPs, the total thickness of $\mathrm{Ag} / \mathrm{Au}$ bilayer was $7 \mathrm{~nm}$ and the ratio of $\mathrm{Ag}$ and $\mathrm{Au}$ was controlled in order to realize the elemental variation in the alloy $\mathrm{NP}$, i.e., $\mathrm{Ag}_{4} \mathrm{Au}_{3}, \mathrm{Ag}_{3.5} \mathrm{Au}_{3.5}$, and $\mathrm{Ag}_{3} \mathrm{Au}_{4}$ bilayers. As-deposited $\mathrm{Ag} / \mathrm{Au}$ bilayers were annealed to induce sufficient surface diffusion, interdiffusion, and agglomeration of atoms, which finally yields the homogeneously intermixed alloy NPs below the melting point of metals [37]. As shown in Fig. $4 \mathrm{a}-\mathrm{c}$, the isolated and self-assembled AgAu alloy NPs of average diameter and height of $\sim 116$ and $\sim 27 \mathrm{~nm}$ were obtained with the bilayers. Although the overall surface morphology of AgAu alloy NPs was similar, a minor deviation in size and configuration was observed due to the variation in the dewetting process with the different ratios of $\mathrm{Ag}$ and $\mathrm{Au}$. It was also found that the diameter and height distribution was slightly wider than the pure $\mathrm{Ag}$ and $\mathrm{Au}$ NPs. In terms of the $R_{\mathrm{q}}$ and $S A R$, they were also found to be similar for all three types of AgAu alloy NPs as presented in Fig. 4d. In the case of reflectance spectra as shown in Fig. 4e, the alloy NPs clearly showed dips in the UV and VIS region corresponding to the quadrupolar or higher-order and dipolar resonance modes. Generally, the reflectance dips were between 480 and $516 \mathrm{~nm}$, which were in the intermediate position between the pure Ag and Au NPs. With the increasing amount of Au in the alloy NPs, the VIS dips were gradually red-shifted as the LSPR of Au occur in the longer VIS wavelength. Meanwhile the average reflectance was decreased with the high $\mathrm{Ag}$ component, indicating the higher absorption in the UV-VIS region. Figure $4 \mathrm{f}$ summaries the atomic percentage of $\mathrm{Ag}$ and $\mathrm{Au}$ atoms in the alloy NPs. The fabricated $\mathrm{AgAu}$ alloy NPs were further investigated with SEM and elemental analysis of $\mathrm{Ag}_{3} \mathrm{Au}_{4}$ sample in Fig. $4 \mathrm{~g}-\mathrm{j}$. As seen in SEM image and elemental phase maps, the NP sites clearly show the homogeneous distribution of $\mathrm{Ag}$ and $\mathrm{Au}$ atoms in NPs. The detailed morphological, elemental, and optical analyses are presented in Figs. S6-S9.

\subsection{Photoresponse of Bimetallic AgAu Alloy NPs}

Figure 5 shows the photocurrent response of alloy NP UV detectors under the illumination of $385 \mathrm{~nm}$ at different power and bias voltages. Like the previous, the linear $I-V$ response was observed at $\pm 0.1 \mathrm{~V}$ with the $\mathrm{Ag}_{4} \mathrm{Au}_{3}, \mathrm{Ag}_{3.5} \mathrm{Au}_{3.5}$, and $\mathrm{Ag}_{3} \mathrm{Au}_{4}$ detectors as shown in Fig. 5a. The dark current was higher with the AgAu alloy NPs. With the UV illumination, the $\mathrm{Ag}_{4} \mathrm{Au}_{3}$ device exhibited the highest photocurrent. The other $\mathrm{Ag}_{3.5} \mathrm{Au}_{3.5}$ and $\mathrm{Ag}_{3} \mathrm{Au}_{4}$ also showed much higher current as compared to the bare $\mathrm{GaN}$ as clearly seen in Fig. 5a, b. Depending upon the elemental composition of alloy NPs, the photocurrent of each device was drastically varied. It was also observed that the photocurrent sharply increased upon turning-on the UV and decay after turning-off for multiple on/off cycles, which infers fast response, good stability, and repeatability of the UV photodetectors. The power-dependent photocurrent enhancement was studied at a constant bias of $0.1 \mathrm{~V}$ as shown in Fig. $5 \mathrm{c}-\mathrm{e}$. Generally, all three devices showed an increasing trend with the power increase, in which the $\mathrm{Ag}_{4} \mathrm{Au}_{3}$ again showed more dynamic and highest photocurrent. The $R, D$, and $E Q E$ for the three photodetectors were calculated and is plotted in Fig. $5 \mathrm{f}-\mathrm{h}$. Compared to 


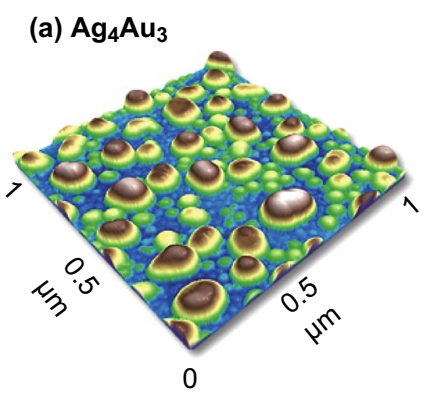

(b) $\mathrm{Ag}_{3.5} \mathrm{Au}_{3.5}$

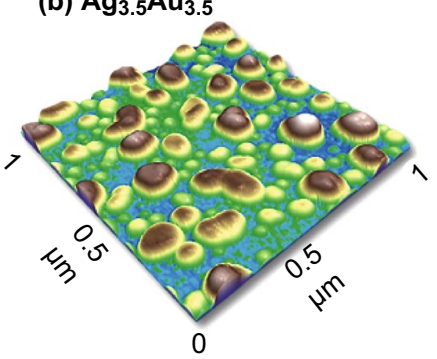

(c) $\mathrm{Ag}_{3} \mathrm{Au}_{4}$

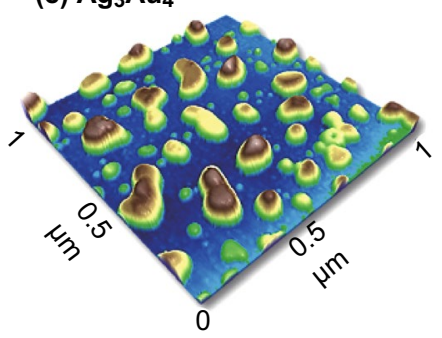

(d)

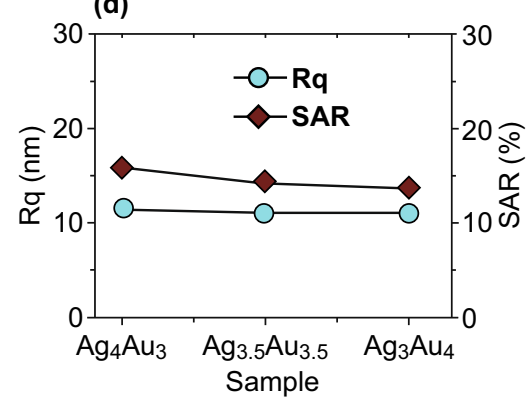

(g) $\mathrm{Ag}_{3} \mathrm{Au}_{4}$

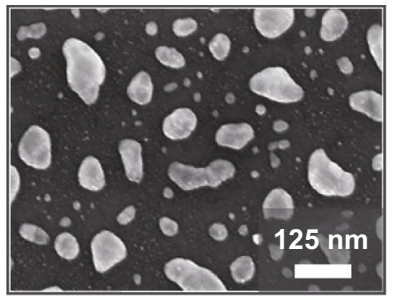

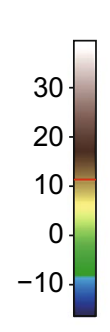

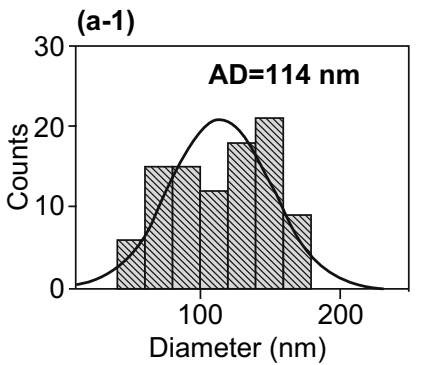

(b-1)
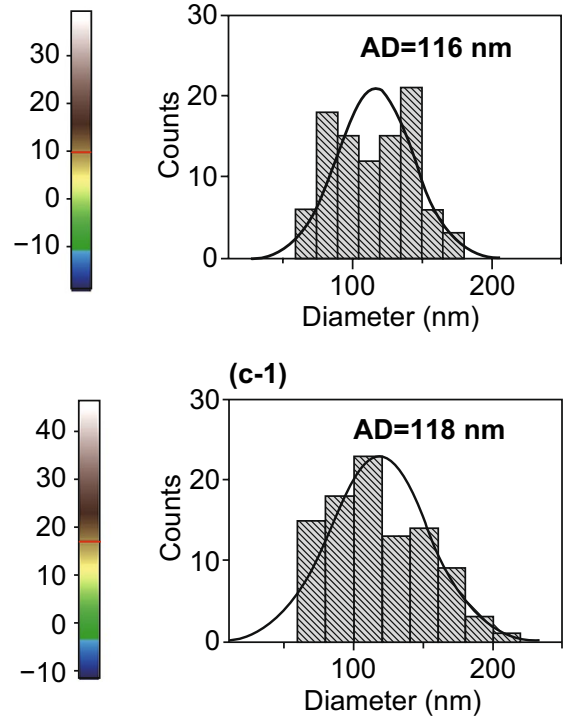

(e)

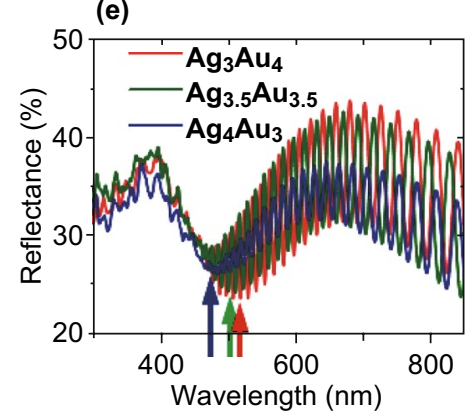

(i) $\mathrm{Au}$

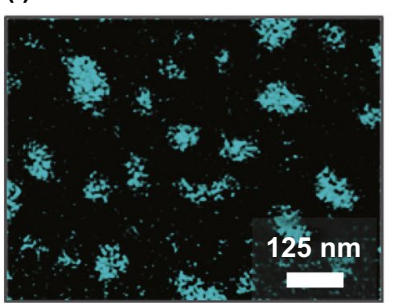

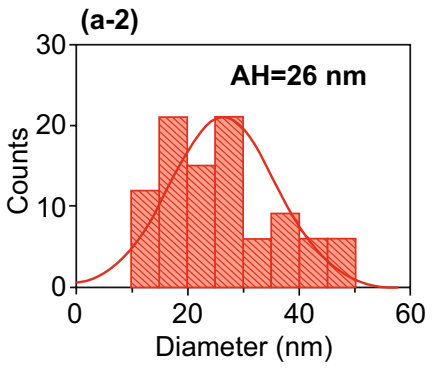

(b-2)
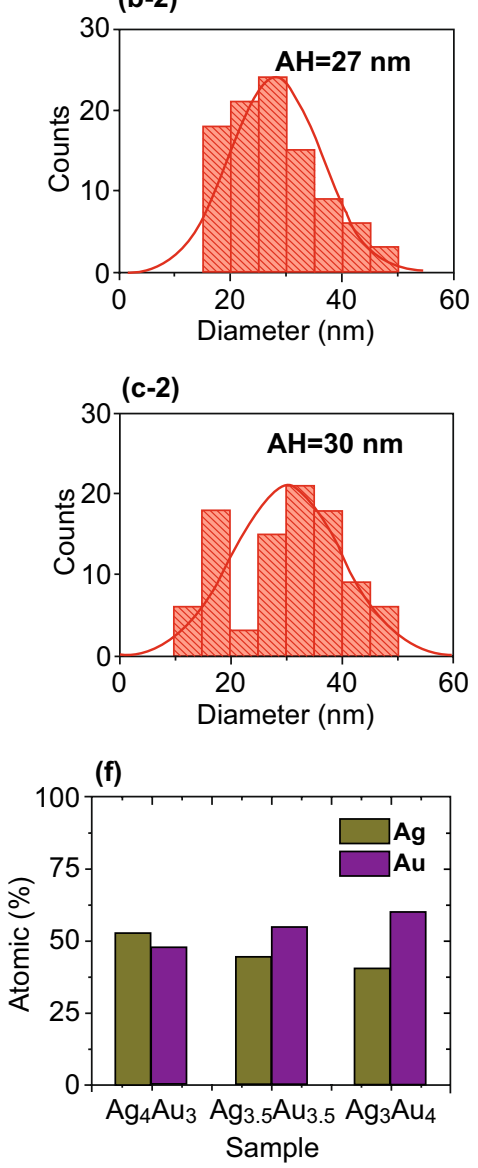

(j) $\mathrm{Ag}$

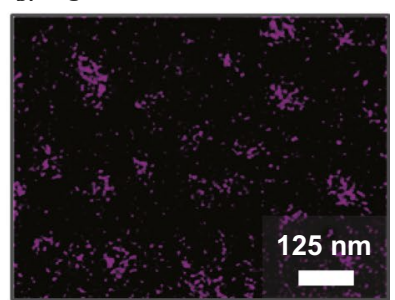

Fig. 4 Surface morphology of $\mathrm{AgAu}$ alloy NPs fabricated on bare $\mathrm{GaN}$ with various thickness ratio of $\mathrm{Ag}$ and $\mathrm{Au}$ in the $\mathrm{Ag}_{\mathrm{x} n \mathrm{~m}} \mathrm{Au} \mathrm{y}_{\mathrm{ym}} \mathrm{bilayers}$. a-c AFM images of the alloy NPs with the $\mathrm{Ag}_{4} \mathrm{Au}_{3}, \mathrm{Ag}_{3.5} \mathrm{Au}_{3.5}$ and $\mathrm{Ag}_{3} \mathrm{Au}_{4}$ bilayers on $\mathrm{GaN}$ - a-1-c-1 Corresponding diameter distribution histograms of alloy NPs. a-2-c-2 Height distribution histograms. d Summary plots of $R_{\mathrm{q}}$ and SAR. e Reflectance spectra. f Summary of the atomic percentage of $\mathrm{Ag}$ and $\mathrm{Au}$ with various thickness ratio. $\mathbf{g}-\mathbf{j}$ SEM image and corresponding elemental maps of Ga, Au, and Ag for the alloy NPs fabricated with the $\mathrm{Ag}_{3} \mathrm{Au}_{4}$ bilayer 


\section{(a) Photo Current}

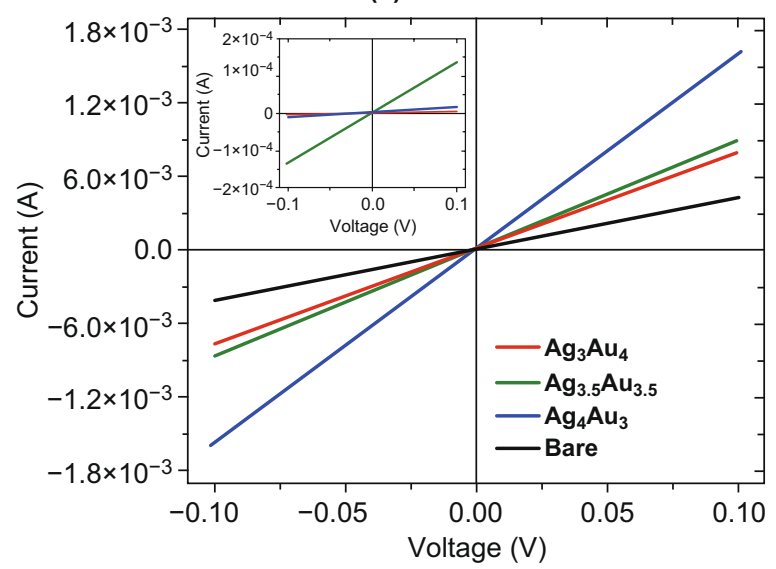

(c) $\mathrm{Ag}_{4} \mathrm{Au}_{3}$

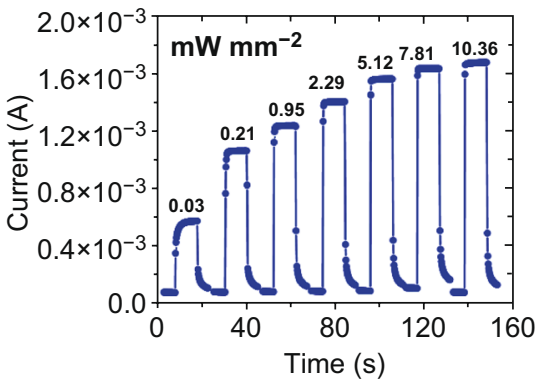

(f) Responsivity

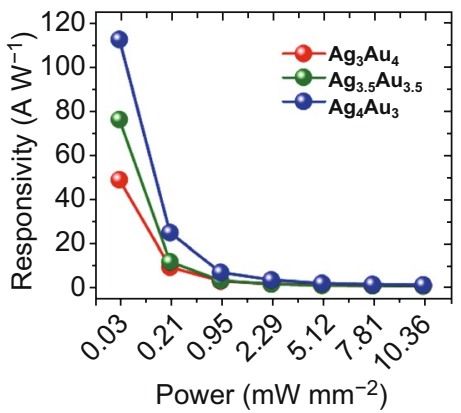

(i) Responsivity

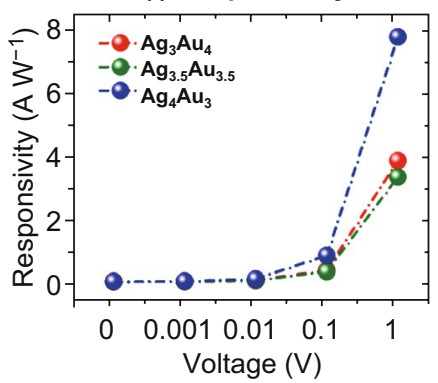

(b) Photo Current

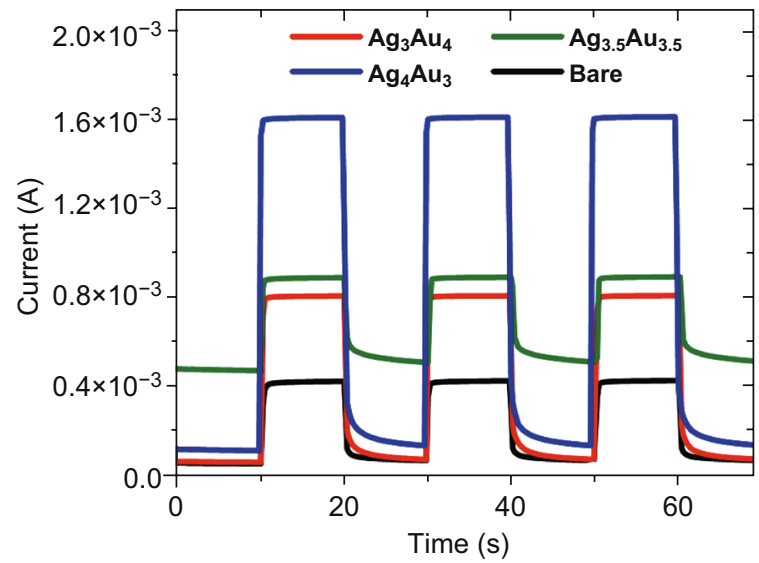

(d) $\mathrm{Ag}_{3.5} \mathrm{Au}_{3.5}$

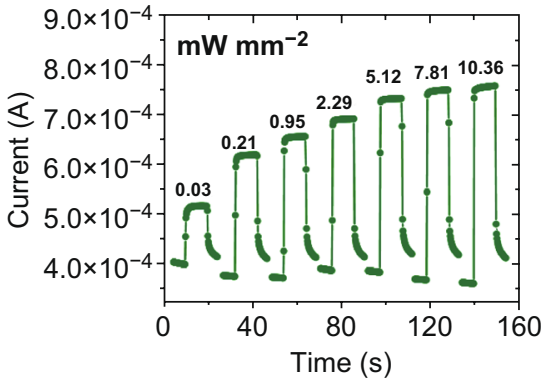

(g) Detectivity

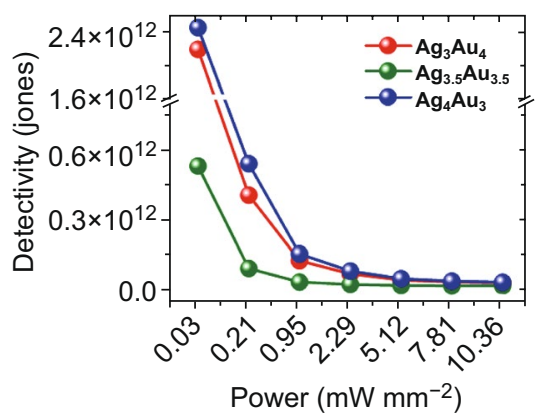

(j) Detectivity

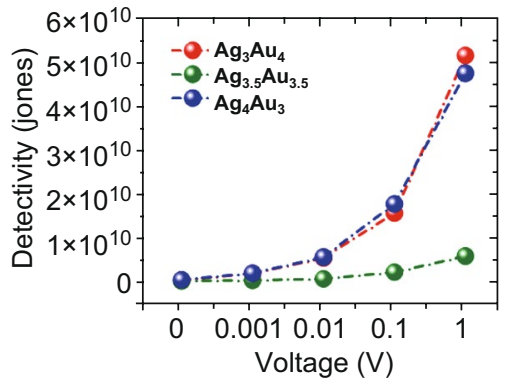

(e) $\mathrm{Ag}_{3} \mathrm{Au}_{4}$

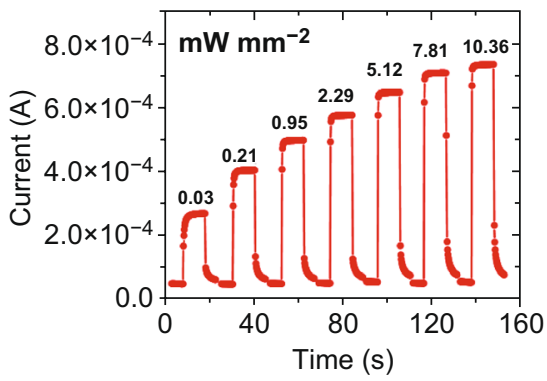

(h) EQE

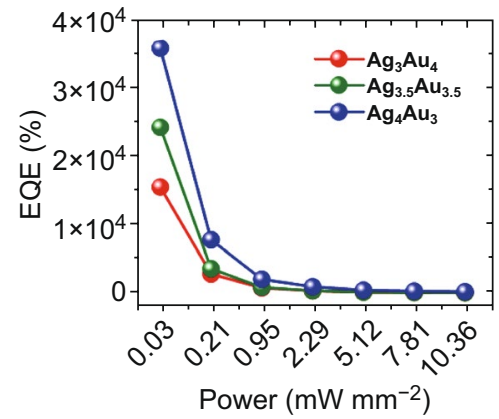

(k) EQE

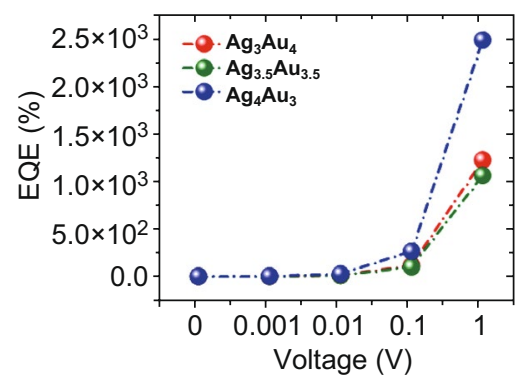

Fig. 5 Photoresponse enhancement of UV photodetectors by the various AgAu alloy NPs under $385 \mathrm{~nm}$ UV illumination. a $I-V$ characteristic under UV illumination and dark for different devices. b Time-resolved photocurrent response at $0.1 \mathrm{~V}$. c-e Light intensity-dependent photoresponse of the devices. $\mathbf{f}-\mathbf{h}$ Summary of the $R, D$, and $E Q E$ as a function of photon power at a constant bias of $0.1 \mathrm{~V}$. i-k Summary of the $R, D$, and $E Q E$ as a function of voltage at a constant power of $10.36 \mathrm{~mW} \mathrm{~mm}^{-2}$ 
the pure $\mathrm{Ag}$ and $\mathrm{Au}$ NP devices, the $\mathrm{Ag}_{4} \mathrm{Au}_{3}$ alloy exhibited a higher photoresponse. For instance, the $R, D$, and $E Q E$ of $\mathrm{Ag}_{4} \mathrm{Au}_{3}$ were $112 \mathrm{~A} \mathrm{~W}^{-1}, 2.4 \times 10^{12}$ jones, and $3.6 \times 10^{4} \%$, respectively, at $0.03 \mathrm{~mW} \mathrm{~mm}^{-2}$ of illumination power, which were higher than those of previously reported GaN-based UV photodetectors with Ag NPs [26], with various GaN films [40, 44-48], and with graphene layers [49-51] as summarized in Table 1. However, the $\mathrm{Ag}_{3.5} \mathrm{Au}_{3.5}$ and $\mathrm{Ag}_{3} \mathrm{Au}_{4}$ devices exhibited somewhat moderate photoresponses with decreasing trend as the Au ratio was increased. Thus, the presence of both $\mathrm{Ag}$ and $\mathrm{Au}$ atom at specific alloy composition could result in the enhanced absorption of UV photons along with the photogenerated carrier in GaN. Specifically, the alloy NPs with the higher Ag percentage showed a better enhancement, which was contrary to the pure $\mathrm{Ag}$ and Au devices in the previous set and will be discussed in the later section. In terms of power-dependent photoresponse, all the alloy NP-based UV photodetectors showed a decreasing trend of the $R, D$, and $E Q E$ as clearly shown in summary plots in Fig. 5f-h. In addition, the performance of the UV photodetectors was examined under different biasing between 0 and $1 \mathrm{~V}$, which showed high stability and repeatability as well as increased photocurrent response. Figure 5i-k summarizes the $R, D$, and $E Q E$ as a function of bias voltage at $10.36 \mathrm{~mW} \mathrm{~mm}^{-2}$, which clearly showed sharp increment in performance parameters with voltage due to the increased carrier drift velocity. The specific values of these device performance parameters are plotted and summarized in Fig. S10 and Tables S4 and S5.
Figure 6a-c shows the self-driven characteristic of the UV photodetectors with the AgAu alloy NP detectors on GaN. The alloy NP photodetectors can be operated at zero bias with the decent stability and repeatability of photocurrent and the current was sharply increased at the UV illumination [32, 34, 36]. Comparing all three alloy NPs devices, the $\mathrm{Ag}_{4} \mathrm{Au}_{3}$ exhibited the highest photocurrent enhancement. Furthermore, it showed the shortest rise and fall time of 0.16 and $0.63 \mathrm{~s}$, respectively, which is similar to the Au device. The fast response and self-driven characteristics of UV detectors are still highly demanded in the field of UV optoelectronics devices. Although much faster response speed and lower dark current of the GaN-based UV photodetectors have been reported recently with the application of $2 \mathrm{D}$ materials and various nanostructured surface morphology on GaN, the alloy NP-based UV photodetector demonstrated in this work was still superior in the overall performance as summarized in Table S5. For example, the $R, D$, and $E Q E$ are much higher with a decent rise and fall time of 0.16 and $0.63 \mathrm{~s}$. In addition, the photoresponse of UV detector was further studied by the fabrication of smaller alloy NPs as presented in Figs. S11-S15 and Tables S6 and S7. Overall photodetector performance was slightly reduced as compared to the larger size alloy NPs, which can be correlated with the reduced plasmonic effect of smaller NP size. At the same time, the higher Ag concentration NP detector, i.e., $\mathrm{Ag}_{3} \mathrm{Au}_{2}$, demonstrated the highest photocurrent as well as the highest $R, D$, and $E Q E$ as a function of photon power variation. In addition, the photodetectors were evaluated in the VIS wavelength. Under the VIS illumination (530 nm

Table 1 Comparision of performance parameters of the GaN-based UV photodetectors with various device configurations and materials reported in recent years

\begin{tabular}{|c|c|c|c|c|c|c|c|}
\hline Materials & $\begin{array}{l}\text { Light source } \\
(\mathrm{nm})\end{array}$ & Bias $(\mathrm{V})$ & $R\left(\mathrm{~A} \mathrm{~W}^{-1}\right)$ & $D$ (jones) & $E Q E(\%)$ & $T_{r}(\mathrm{~ms})$ & $T_{f}(\mathrm{~ms})$ \\
\hline GaN nanoflowers [34] & 325 & 1 & 10.5 & & & 67 & 24 \\
\hline Ag NPs/GaN [35] & 360 & 5 & 4 & & & & \\
\hline GaN film [40] & 325 & 5 & 0.34 & $1.24 \times 10^{9}$ & & 280 & 450 \\
\hline Graphene/GaN [44] & 325 & 10 & 0.361 & $2.3 \times 10^{10}$ & 87.5 & 5.05 & 5.11 \\
\hline Graphene/GaN [45] & 365 & 7 & 0.003 & & & & \\
\hline r-GO/GaN [46] & 350 & 0 & 0.0015 & $1.45 \times 10^{10}$ & & 60 & 267 \\
\hline$\beta-\mathrm{Ga}_{2} \mathrm{O}_{3} / \mathrm{GaN}$ [39] & 365 & 5 & 3.7 & $4.7 \times 10^{10}$ & 100 & & \\
\hline a-plane GaN [41] & 365 & 5 & 1.35 & & & 46 & 75 \\
\hline a-plane GaN [42] & 365 & 2 & 0.74 & & & 57 & 13 \\
\hline $\mathrm{ZnO} / \mathrm{GaN}$ [43] & 300 & 0 & 0.176 & $2.5 \times 10^{12}$ & & 350 & 350 \\
\hline $\mathrm{Ag}_{4} \mathrm{Au}_{3} / \mathrm{GaN}$ & 385 & 0.1 & 112 & $2.4 \times 10^{12}$ & $3.6 \times 10^{4}$ & 160 & 630 \\
\hline
\end{tabular}


(a) $\mathrm{Ag}_{4} \mathrm{Au}_{3}$
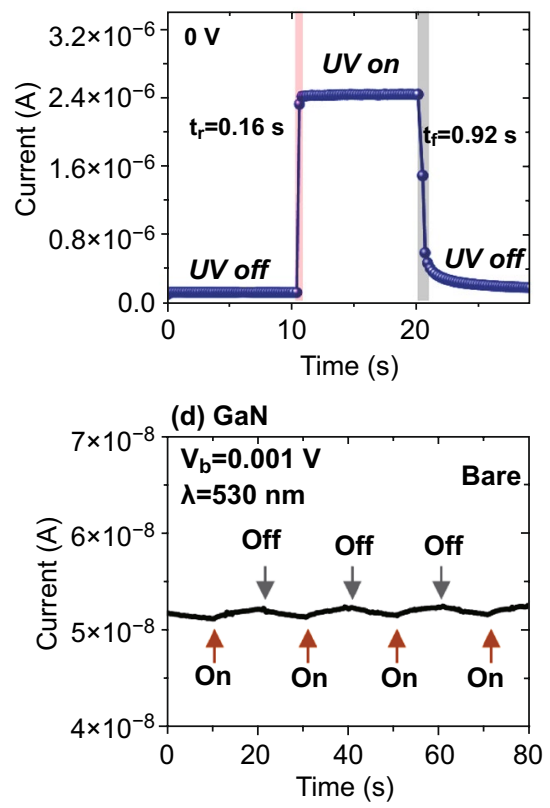

(g) $\mathrm{Ag}$

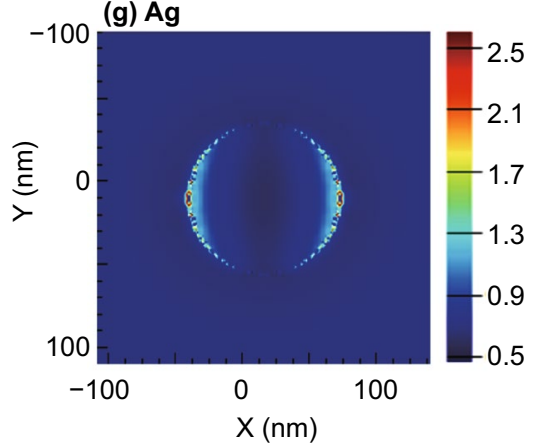

(j)

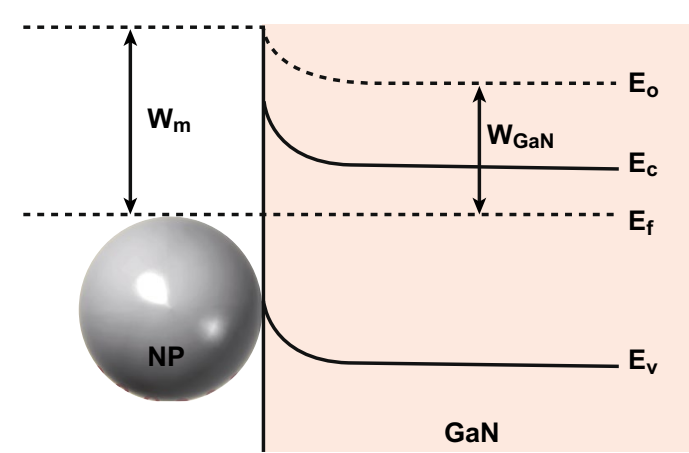

(b) $\mathrm{Ag}_{3.5} \mathrm{Au}_{3.5}$

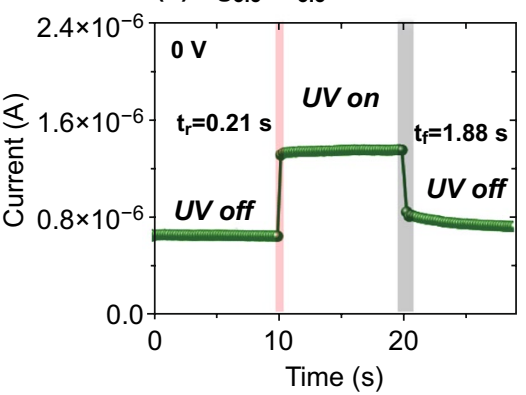

(e) $\mathrm{Ag}_{4} \mathrm{Au}_{3}$

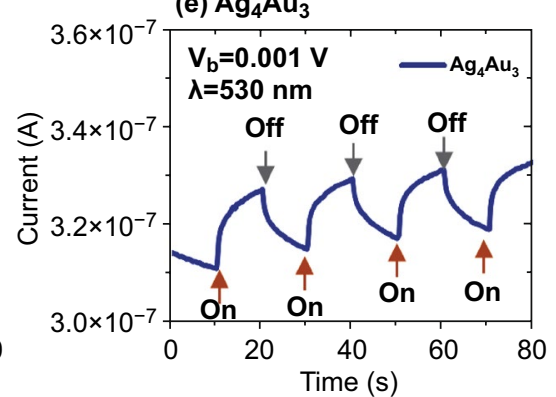

(h) Au

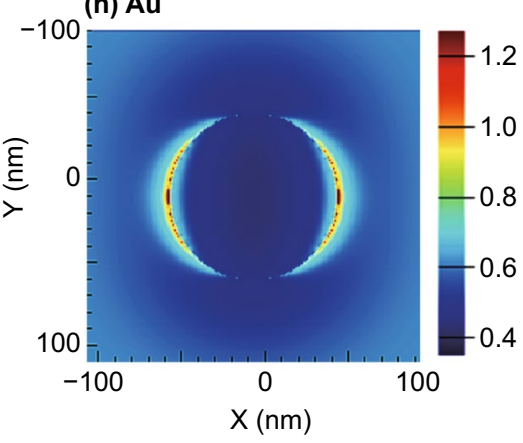

(c) $\mathrm{Ag}_{3} \mathrm{Au}_{4}$
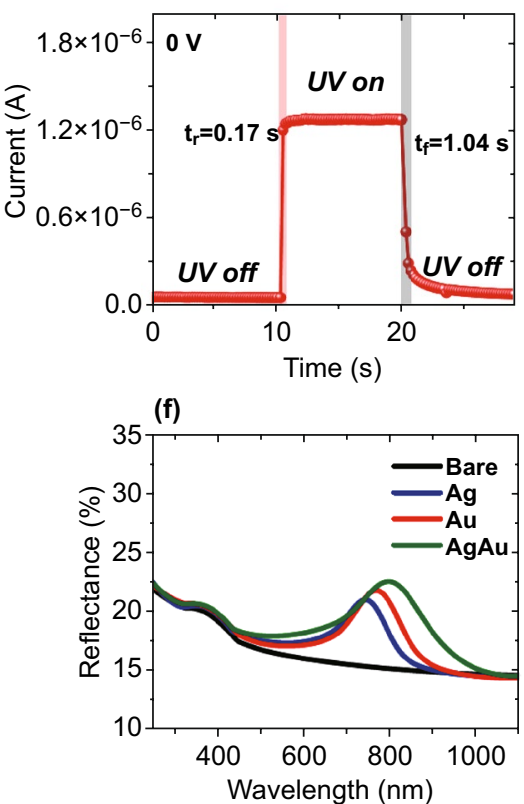

(i) $\mathrm{Ag}_{0.6} \mathrm{Au}_{0.4}$

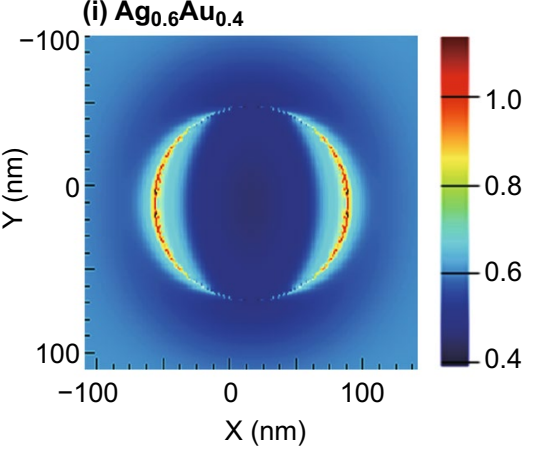

(k) UV On LSPR excited carrier transfer

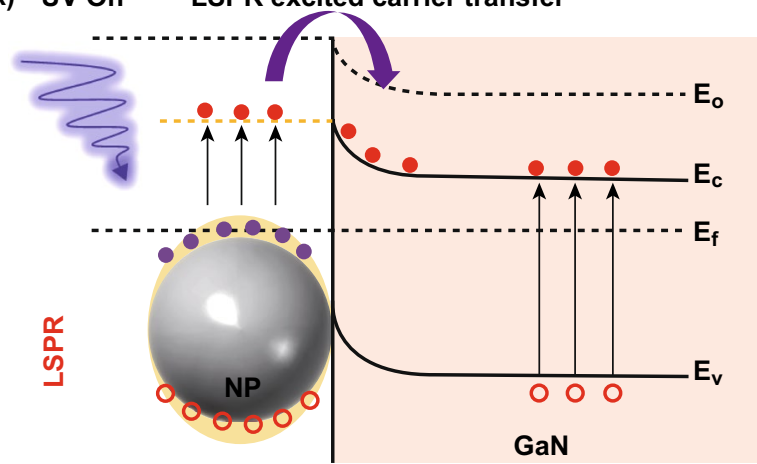

Fig. 6 a-c Photoresponse of the $\mathrm{Ag}_{4} \mathrm{Au}_{3}, \mathrm{Ag}_{3.5} \mathrm{Au}_{3.5}$, and $\mathrm{Ag}_{3} \mathrm{Au}_{4}$ photodetectors under $385 \mathrm{~nm} \mathrm{UV}$ illumination $\left(10.36 \mathrm{~mW} \mathrm{~mm}{ }^{-2}\right)$ at $0 \mathrm{~V}$. d, e $I-t$ characteristic under the illumination of $530 \mathrm{~nm}$ at $1 \mathrm{mV}$ for the bare $\mathrm{GaN}$ and $\mathrm{Ag}_{4} \mathrm{Au}_{3}$ photodetectors. f FDTD simulated reflectance spectra of the typical $\mathrm{Ag}, \mathrm{Au}$ and $\mathrm{Ag}_{0.6} \mathrm{Au}_{0.4}$ alloy NPs. $\mathbf{g}-\mathbf{i}$ Corresponding e-field distribution of the typical NPs at $385 \mathrm{~nm}$ excitation. $\mathbf{j}-\mathbf{k}$ Schematics of the energy band diagrams of the NP photodetector and the charge transfer process under UV illumination

at $\sim 3 \mathrm{~mW} \mathrm{~mm}^{-2}$ ), the bare GaN photodetector exhibited almost negligible photocurrent as shown in Fig. $6 \mathrm{~d}$ because of the photon energy less than the bandgap of GaN. At the same time, the photoresponse became noticeable and got stronger with the $\mathrm{Ag}_{4} \mathrm{Au}_{3} \mathrm{NPs}$, which can be correlated to the enhanced absorption of VIS wavelength due to the LSPR 
on the alloy NPs [27-29]. In contrast to the UV response, the VIS photoresponse was very minor and gradually increased.

\subsection{Photoresponse Enhancement Mechanism}

Finally, the underlying mechanism associated with the photocurrent enhancement of the UV photodetectors with plasmonic NPs can be discussed based on the interaction between incident photon and NPs and energy band theory as shown in Fig. 6f-k. Firstly, the electromagnetic interaction of various NPs with incident photons was elucidated by the FDTD simulations. The simulated reflectance in Fig. 6f and localized e-fields of the typical Ag, $\mathrm{Au}$, and $\mathrm{Ag}_{4} \mathrm{Au}_{3}$ NPs are presented in Fig. 6g-j and the transmittance and extinction spectra are provided in Fig. S8. The simulated spectra also clearly showed dips and peaks in the UV and VIS regions followed by peaks due to the LSPR of the NPs whereas nearly flat response was obtained with bare GaN [39]. The plasmonic effect was successively enhanced with the $\mathrm{Ag}, \mathrm{Au}$, and $\mathrm{Ag}_{4} \mathrm{Au}_{3}$ alloy NPs, which was indicated by the stronger peaks and dips in reflectance spectra. In addition, the localized e-field distribution of $\mathrm{Ag}, \mathrm{Au}$, and $\mathrm{Ag}_{0.6} \mathrm{Au}_{0.4}$ alloy NPs also exhibited much stronger and broader optical near-field enhancement accordingly. As seen in Fig. 6g-j, the e-field distribution of Ag NPs was mostly confined at the edges whereas the $\mathrm{Au}$ and $\mathrm{Ag}_{0.6} \mathrm{Au}_{0.4}$ alloy NPs showed much wider distribution. From the simulation of optical spectra and e-field, it was clear that the LSPR inherently varied based upon the surface morphology and the elemental composition of NPs such as the $\mathrm{Ag}_{0.6} \mathrm{Au}_{0.4}$ alloy NPs have the strongest LSPR and then gradually reduced with the Au and Ag NPs. On the other hand, upon UV excitation the Ag and Au NPs induce the intraband and interband excitation of electrons known as hot carriers associated with the nonradiative plasmonic decay [27, 52]. The excited surface plasmon in metal NPs can decay by generating and elelctron-hole pair with much larger energy than the carriers near the Fermi energy [53]. From the time-resolved photoresponse, it was found that the bare GaN and NPs/GaN samples show instant current increase after LED is switched on and become steady. This process implies that the response can be mainly dominated by the ultrafast hot electron injection rather than photothermal effect and localize e-field enhancement [52]. Although the photoresponce in our device could be partially contributed each of these effects but the hot electron excitation and injection can be more dominant phenomenon. It also should be noted that the hot electron injection efficiency vary with the composition of alloy NPs such that the higher Ag concentration can offer more hot electron transfer due to the shifting of interband threshold energy [27]. Therefore, as compared to the pure Au and Ag NPs, much-enhanced light absorption and hot electron transfer can result in the increased photocurrent generation with the alloy NP. Meanwhile, for the large size NPs, the LSPR effect can also be contributed by high forward scattering towards the GaN interface, which is more stronger with the $\mathrm{Au}$ than $\mathrm{Ag}$ and likely generates additional electron-hole pairs in GaN bandgap [54, 55]. In addition, the photocurrent enhancement of the UV photodetectors largely depends upon the energy band of metallic NPs and GaN. Generally, the work function of $\mathrm{Ag}(4.26-4.7 \mathrm{eV})$ and $\mathrm{Au}(5.10-5.47 \mathrm{eV})$ is higher than the n-type $\mathrm{GaN}(4.2 \mathrm{eV})$ and thus the energy band aligns as presented in Fig. $6 \mathrm{j}$ to match the Fermi level when the metal NPs and GaN are brought in contact under dark conditions [56]. However, the Schottky barrier height can vary for $\mathrm{Ag}, \mathrm{Au}$, and $\mathrm{AgAu}$ devices. For the complete miscible binary metal, the work function for the alloy composition can be estimated based on the mass fraction as given by the relation as Eq. 5:

$\varnothing\left(A g_{x} A u_{1-x}\right)=x \times \varnothing(A g)+(1-x) \times \varnothing(A u)$

where $\emptyset(A g)$ and $\emptyset(A u)$ are the work functions of pure $\mathrm{Ag}$ and $\mathrm{Au}$, respectively $[57,58]$. Based on the work function of different metals, the $\mathrm{Ag}, \mathrm{AgAu}$, and $\mathrm{Au}$ could possess the lowest, medium, and highest barrier height, respectively. Therefore, the conductivity of Ag photodetector under dark conditions can be higher as compared to the pure Au. However, the $\mathrm{Ag}_{3.5} \mathrm{Au}_{3.5}$ showed exceptionally high dark current, which can be due to the difference in the surface composition and crystal facets that could also largely affect the work function in the alloy phase [59]. Under the UV light illumination, the energy from the photons can be absorbed by the GaN to generate electron-hole pairs as shown in Fig. 6j, which contributes to the photocurrent generation in the device. Meanwhile, the electromagnetic fields on the NPs can also be enhanced due to the collective oscillation of electrons and the excited hot electrons from the metallic NPs spontaneously transfer to the conduction band of GaN. Therefore, the overall photocurrent of the device can be largely enhanced by the plasmonic NPs on the GaN. In our case, the $\mathrm{AgAu}$ alloy composition with the higher $\mathrm{Ag}$ 
percentage exhibited the highest performance parameters as compared to other pure and alloy NPs, which could be attributed to the combined effect of enhanced plasmonic absorption and the decreased barrier height at the GaN interface.

\section{Conclusions}

In summary, the photoresponse of UV photodetectors was studied with the mono- and bimetallic NPs of the different size and elemental compositions on GaN (0001) based on the solid-state dewetting approach. The dynamic and improved photoresponse of UV photodetectors has been demonstrated with various monometallic $\mathrm{Ag}$ and $\mathrm{Au}$ and bimetallic AgAu alloy NPs. Specifically, the AgAu alloy NPs with the higher Ag percentage exhibited the highest responsivity of $112 \mathrm{~A} \mathrm{~W}^{-1}$, detectivity of $2.4 \times 10^{12}$ jones, and $E Q E$ of $3.6 \times 10^{4} \%$ under $0.03 \mathrm{~mW} \mathrm{~mm}^{-2}$ at $0.1 \mathrm{~V}$, which is a superior result as compared to the previously reported GaN-based UV photodetectors. The fabricated UV photodetectors were operated at comparatively low voltage, i.e., below $1 \mathrm{~V}$, or even at no bias (self-driven mode) and have demonstrated very sensitive and stable photocurrent responses. In the alloy NPs, the increased concentration of Ag resulted in an improved performance as being benefitting from the enhanced light absorption and scattering, hot electron transfer and reduced barrier height at the $\mathrm{GaN}$ interface. Furthermore, the photocurrent was significantly enhanced without sacrificing the response time as compared to the bare $\mathrm{GaN}$ devices. The mechanism of photocurrent enhancement was systematically discussed with the help of FDTD simulation and band theory of metallic NPs and GaN. This work could be of great potentials for advancing GaN-based UV detectors.

Acknowledgements Financial support from the National Research Foundation of Korea (NRF) Grant funded by the Korean Government (MSIP) (Nos. NRF-2019R1A2C4069438 and NRF-2018R1A6A1A03025242) and in part by the research grant of Kwangwoon University in 2020 is gratefully acknowledged. Special appreciations to Ms. So Hee Kim from the Korea Institute of Science and Technology (KIST) for the SEM-EDX characterizations.

Open Access This article is licensed under a Creative Commons Attribution 4.0 International License, which permits use, sharing, adaptation, distribution and reproduction in any medium or format, as long as you give appropriate credit to the original author(s) and the source, provide a link to the Creative Commons licence, and indicate if changes were made. The images or other third party material in this article are included in the article's Creative Commons licence, unless indicated otherwise in a credit line to the material. If material is not included in the article's Creative Commons licence and your intended use is not permitted by statutory regulation or exceeds the permitted use, you will need to obtain permission directly from the copyright holder. To view a copy of this licence, visit http://creativecommons.org/licenses/by/4.0/.

Electronic supplementary material The online version of this article (https://doi.org/10.1007/s40820-020-00437-x) contains supplementary material, which is available to authorized users.

\section{References}

1. H. Chen, K. Liu, L. Hu, A.A. Al-Ghamdi, X. Fang, New concept ultraviolet photodetectors. Mater. Today 18, 493-502 (2015). https://doi.org/10.1016/j.mattod.2015.06.001

2. R.P. Gajula, S. Gaddameedhi, Commentary: Chemiexcitation of melanin derivatives induces DNA photoproducts long after UV exposure. Front. Physiol. 6, 842-848 (2015). https://doi. org/10.3389/fphys.2015.00276

3. H. Chen, H. Liu, Z. Zhang, K. Hu, X. Fang, Nanostructured photodetectors: from ultraviolet to terahertz. Adv. Mater. 28, 403-433 (2016). https://doi.org/10.1002/adma.201503534

4. Y. Wang, Y. Qian, X. Kong, Photon counting based on solarblind ultraviolet intensified complementary metal-oxidesemiconductor (ICMOS) for corona detection. IEEE Photonics J. 10, 7000919 (2018). https://doi.org/10.1109/JPHOT .2018 .2876514

5. M. Tan, C. Hu, Y. Lan, J. Khan, H. Deng et al., 2D lead dihalides for high-performance ultraviolet photodetectors and their detection mechanism investigation. Small 13, 1702024 (2017). https://doi.org/10.1002/smll.201702024

6. M. Kikawada, A. Ono, W. Inami, Y. Kawata, Enhanced multicolor fluorescence in bioimaging using deep-ultraviolet surface plasmon resonance. Appl. Phys. Lett. 104, 223703 (2014). https://doi.org/10.1063/1.4881325

7. J. An, T.S.D. Le, C.H.J. Lim, V.T. Tran, Z. Zhan et al., Singlestep selective laser writing of flexible photodetectors for wearable optoelectronics. Adv. Sci. 5, 1800496 (2018). https://doi. org/10.1002/advs.201800496

8. L. Li, L. Gu, Z. Lou, Z. Fan, G. Shen, ZnO quantum dot decorated $\mathrm{Zn}_{2} \mathrm{SnO}_{4}$ nanowire heterojunction photodetectors with drastic performance enhancement and flexible ultraviolet image sensors. ACS Nano 11, 4067-4076 (2017). https://doi. org/10.1021/acsnano.7b00749

9. Y. Wang, Y. Chen, W. Zhao, L. Ding, L. Wen et al., A selfpowered fast-response ultraviolet detector of $\mathrm{p}$-n homojunction assembled from two $\mathrm{ZnO}$-based nanowires. Nano-Micro Lett. 9, 11 (2017). https://doi.org/10.1007/s40820-016-0112-6

10. D.M. Reilly, D.T. Moriarty, J.A. Maynard, Unique properties of solar blind ultraviolet communication systems for 
unattended ground-sensor networks. Unmanned/Unattended Sens. Sens. Netw. 5611, 244 (2004). https://doi. org/10.1117/12.582002

11. G. Wang, H. Lu, D. Chen, F. Ren, R. Zhang et al., High quantum efficiency GaN-based p-i-n ultraviolet photodetectors prepared on patterned sapphire substrates. IEEE Photonics Technol. Lett. 25, 652-654 (2013). https://doi.org/10.1109/ LPT.2013.2248056

12. F. Xie, H. Lu, X. Xiu, D. Chen, P. Han et al., Low dark current and internal gain mechanism of GaN MSM photodetectors fabricated on bulk GaN substrate. Solid State Electron. 57, 39-42 (2011). https://doi.org/10.1016/j.sse.2010.12.005

13. J.H. Kang, M.A. Johar, B. Alshehri, E. Dogheche, S.W. Ryu, Facile growth of density- and diameter-controlled GaN nanobridges and their photodetector application. J. Mater. Chem. C 5, 11879-11884 (2017). https://doi.org/10.1039/C7TC02619F

14. X. Zhang, Q. Liu, B. Liu, W. Yang, J. Li et al., Giant UV photoresponse of a GaN nanowire photodetector through effective Pt nanoparticle coupling. J. Mater. Chem. C 5, 4319-4326 (2017). https://doi.org/10.1039/C7TC00594F

15. M.-Y. Li, M. Yu, D. Su, J. Zhang, S. Jiang et al., Ultrahigh responsivity UV photodetector based on $\mathrm{Cu}$ nanostructure/ ZnO QD hybrid architectures. Small 15, 1901606 (2019). https ://doi.org/10.1002/smll.201901606

16. Z. Kang, Y. Cheng, Z. Zheng, F. Cheng, Z. Chen et al., $\mathrm{MoS}_{2}$-based photodetectors powered by asymmetric contact structure with large work function difference. NanoMicro Lett. 11, 34 (2019). https://doi.org/10.1007/s4082 0-019-0262-4

17. L. Liu, C. Yang, A. Patanè, Z. Yu, F. Yan et al., High-detectivity ultraviolet photodetectors based on laterally mesoporous GaN. Nanoscale 9, 8142-8148 (2017). https://doi.org/10.1039/ C7NR01290J

18. J.H. Lee, W.W. Lee, D.W. Yang, W.J. Chang, S.S. Kwon et al., Anomalous photovoltaic response of graphene-onGaN Schottky photodiodes. ACS Appl. Mater. Interfaces 10, 14170-14174 (2018). https://doi.org/10.1021/acsami.8b02043

19. D. Li, X. Sun, H. Song, Z. Li, H. Jiang et al., Effect of asymmetric Schottky barrier on GaN-based metal-semiconductormetal ultraviolet detector. Appl. Phys. Lett. 99, 1-4 (2011). https://doi.org/10.1063/1.3672030

20. R. Zhuo, Y. Wang, D. Wu, Z. Lou, Z. Shi et al., High-performance self-powered deep ultraviolet photodetector based on $\mathrm{MoS}_{2} / \mathrm{GaN}$ p-n heterojunction. J. Mater. Chem. C 6, 299-303 (2018). https://doi.org/10.1039/C7TC04754A

21. X. Zhang, J. Li, W. Yang, B. Leng, P. Niu et al., High-performance flexible ultraviolet photodetectors based on $\mathrm{AZO} / \mathrm{ZnO} /$ PVK/PEDOT:PSS heterostructures integrated on human hair. ACS Appl. Mater. Interfaces 11, 24459-24467 (2019). https ://doi.org/10.1021/acsami.9b07423

22. J. Kim, H.C. Lee, K.H. Kim, M.S. Hwang, J.S. Park et al., Photon-triggered nanowire transistors. Nat. Nanotechnol. 12, 963-968 (2017). https://doi.org/10.1038/nnano.2017.153

23. X. Zhang, B. Liu, Q. Liu, W. Yang, C. Xiong et al., Ultrasensitive and highly selective photodetections of UV: a rays based on individual bicrystalline GaN nanowire. ACS Appl. Mater. Interfaces 9, 2669-2677 (2017). https://doi.org/10.1021/acsam i.6b14907

24. Y. Tian, S.J. Chua, H. Wang, Theoretical study of characteristics in GaN metal-semiconductor-metal photodetectors. Solid State Electron. 47, 1863-1867 (2003). https://doi.org/10.1016/ S0038-1101(03)00184-9

25. J.A. Garrido, E. Monroy, I. Izpura, E. Muñoz, Photoconductive gain modelling of $\mathrm{GaN}$ photodetectors. Semicond. Sci. Technol. 13, 563-568 (1998). https://doi. org/10.1088/0268-1242/13/6/005

26. D. Li, X. Sun, H. Song, Z. Li, Y. Chen et al., Realization of a high-performance GaN UV detector by nanoplasmonic enhancement. Adv. Mater. 24, 845-849 (2012). https://doi. org/10.1002/adma.201102585

27. M. Valenti, A. Venugopal, D. Tordera, M.P. Jonsson, G. Biskos et al., Hot carrier generation and extraction of plasmonic alloy nanoparticles. ACS Photonics 4, 1146-1152 (2017). https:// doi.org/10.1021/acsphotonics.6b01048

28. M. Reddeppa, S.B. Mitta, T. Chandrakalavathi, B.G. Park, G. Murali et al., Solution-processed Au@rGO/GaN nanorods hybrid-structure for self-powered UV, visible photodetector and CO gas sensors. Curr. Appl. Phys. 19, 938-945 (2019). https://doi.org/10.1016/j.cap.2019.05.008

29. S. Liu, M.Y. Li, D. Su, M. Yu, H. Kan et al., Broad-band high-sensitivity $\mathrm{ZnO}$ colloidal quantum dots/self-assembled au nanoantennas heterostructures photodetectors. ACS Appl. Mater. Interfaces 10, 32516-32525 (2018). https://doi. org/10.1021/acsami.8b09442

30. D. Rioux, S. Vallières, S. Besner, P. Muñoz, E. Mazur et al., An analytic model for the dielectric function of $\mathrm{Au}, \mathrm{Ag}$, and their alloys. Adv. Opt. Mater. 2, 176-182 (2014). https://doi. org/10.1002/adom.201300457

31. T. Kawashima, H. Yoshikawa, S. Adachi, S. Fuke, K. Ohtsuka, Optical properties of hexagonal GaN. J. Appl. Phys. 82, 3528-3535 (1997). https://doi.org/10.1063/1.365671

32. M. Sui, P. Pandey, M.Y. Li, Q. Zhang, S. Kunwar et al., Tuning the configuration of Au nanostructures: from vermiform-like, rod-like, triangular, hexagonal, to polyhedral nanostructures on c-plane GaN. J. Mater. Sci. 52, 391-407 (2017). https://doi. org/10.1007/s10853-016-0339-0

33. S. Kunwar, M. Sui, Q. Zhang, P. Pandey, M.Y. Li et al., Various silver nanostructures on sapphire using plasmon selfassembly and dewetting of thin films. Nano-Micro Lett. 9, 17 (2017). https://doi.org/10.1007/s40820-016-0120-6

34. A. Kosinova, O. Kovalenko, L. Klinger, E. Rabkin, Mechanisms of solid-state dewetting of thin Au films in different annealing atmospheres. Acta Mater. 83, 91-101 (2015). https ://doi.org/10.1016/j.actamat.2014.09.049

35. L.T. Kong, L.J. Lewis, Surface diffusion coefficients: substrate dynamics matters. Phys. Rev. B-Condens. Matter Mater. Phys. 77, 1-5 (2008). https://doi.org/10.1103/PhysRevB.77.165422

36. T. Tian, L. Wang, E. Guo, Z. Liu, T. Zhan et al., Optimized subsequent-annealing-free $\mathrm{Ni} / \mathrm{Ag}$ based metallization contact 
to p-type $\mathrm{GaN}$ for vertical light emitting diodes with high yield and extremely low operating voltage (2.75 V@ $350 \mathrm{~mA}$, \%3e95\%). J. Phys. D-Appl. Phys. 47, 115102 (2014). https:// doi.org/10.1088/0022-3727/47/11/115102

37. M. Kang, M.-S. Ahn, Y. Lee, K.-H. Jeong, Bioplasmonic alloyed nanoislands using dewetting of bilayer thin films. ACS Appl. Mater. Interfaces 9, 37154-37159 (2017). https://doi. org/10.1021/acsami.7b10715

38. P.J. Rivero, E. Ibañez, J. Goicoechea, A. Urrutia, I.R. Matias et al., A self-referenced optical colorimetric sensor based on silver and gold nanoparticles for quantitative determination of hydrogen peroxide. Sens. Actuators B-Chem. 251, 624-631 (2017). https://doi.org/10.1016/j.snb.2017.05.110

39. K.L. Kelly, E. Coronado, L.L. Zhao, G.C. Schatz, The optical properties of metal nanoparticles: the influence of size, shape, and dielectric environment. J. Phys. Chem. B 107, 668-677 (2003). https://doi.org/10.1021/jp026731y

40. N. Aggarwal, S. Krishna, A. Sharma, L. Goswami, D. Kumar et al., A highly responsive self-driven UV photodetector using GaN nanoflowers. Adv. Electron. Mater. 3, 1-7 (2017). https ://doi.org/10.1002/aelm.201700036

41. M. Peng, Y. Liu, A. Yu, Y. Zhang, C. Liu et al., Flexible selfpowered gan ultraviolet photoswitch with piezo-phototronic effect enhanced on/off ratio. ACS Nano 10, 1572-1579 (2016). https://doi.org/10.1021/acsnano.5b07217

42. S. Chang, M. Chang, Y. Yang, Enhanced responsivity of GaN metal-semiconductor-metal (MSM) photodetectors on GaN substrate. IEEE Photonics J. 9, 1-7 (2017). https://doi. org/10.1109/JPHOT.2017.2688520

43. A.M. Brown, R. Sundararaman, P. Narang, W.A. Goddard, H.A. Atwater, Nonradiative plasmon decay and hot carrier dynamics: effects of phonons, surfaces, and geometry. ACS Nano 10, 957-966 (2016). https://doi.org/10.1021/acsna no. 5 b06199

44. A. Kalra, S. Vura, S. Rathkanthiwar, R. Muralidharan, S. Raghavan et al., Demonstration of high-responsivity epitaxial $\beta-\mathrm{Ga}_{2} \mathrm{O}_{3} / \mathrm{GaN}$ metal-heterojunction-metal broadband UV-A/ UV-C detector. Appl. Phys. Express 11, 064101 (2018). https ://doi.org/10.7567/APEX.11.064101

45. A. Gundimeda, S. Krishna, N. Aggarwal, A. Sharma, N.D. Sharma et al., Fabrication of non-polar GaN based highly responsive and fast UV photodetector. Appl. Phys. Lett. 110, 103507 (2017). https://doi.org/10.1063/1.4978427

46. W. Wang, Y. Zheng, X. Li, Y. Li, L. Huang et al., High-performance nonpolar: a-plane $\mathrm{GaN}$-based metal-semiconductormetal UV photo-detectors fabricated on $\mathrm{LaAlO}_{3}$ substrates. J. Mater. Chem. C 6, 3417-3426 (2018). https://doi.org/10.1039/ C7TC05534J

47. W. Wang, Z. Yang, Z. Lu, G. Li, High responsivity and low dark current nonpolar GaN-based ultraviolet photo-detectors.
J. Mater. Chem. C 6, 6641-6646 (2018). https://doi. org/10.1039/C8TC02281J

48. H. Zhou, P. Gui, L. Yang, C. Ye, M. Xue et al., High performance, self-powered ultraviolet photodetector based on a $\mathrm{ZnO}$ nanoarrays/GaN structure with a $\mathrm{CdS}$ insert layer. New J. Chem. 41, 4901-4907 (2017). https://doi.org/10.1039/C7NJ0 $1140 \mathrm{G}$

49. H. Tian, Q. Liu, A. Hu, X. He, Z. Hu et al., Hybrid graphene/ GaN ultraviolet photo-transistors with high responsivity and speed. Opt. Express 26, 5408-5415 (2018). https://doi. org/10.1364/OE.26.005408

50. C.J. Lee, S.B. Kang, H.G. Cha, C.H. Won, S.K. Hong et al., GaN metal-semiconductor-metal UV sensor with multi-layer graphene as Schottky electrodes. Jpn. J. Appl. Phys. (2015). https://doi.org/10.7567/JJAP.54.06FF08

51. N. Prakash, M. Singh, G. Kumar, A. Barvat, K. Anand et al., Ultrasensitive self-powered large area planar GaN UV-photodetector using reduced graphene oxide electrodes. Appl. Phys. Lett. 109, 242102 (2016). https://doi.org/10.1063/1.4971982

52. L. Wen, Y. Chen, W. Liu, Q. Su, J. Grant et al., Enhanced photoelectric and photothermal responses on silicon platform by plasmonic absorber and Omni-Schottky junction. Laser Photonics Rev. 11, 1-10 (2017). https://doi.org/10.1002/ lpor.201700059

53. M. Kim, M. Lin, J. Son, H. Xu, J.M. Nam, Hot-electron-mediated photochemical reactions: principles, recent advances, and challenges. Adv. Opt. Mater. 5, 1-21 (2017). https://doi. org/10.1002/adom.201700004

54. A. Paris, A. Vaccari, A. Calà Lesina, E. Serra, L. Calliari, Plasmonic scattering by metal nanoparticles for solar cells. Plasmonics 7, 525-534 (2012). https://doi.org/10.1007/s 1146 8-012-9338-4

55. R. Jia, D. Zhao, N. Gao, D. Liu, Polarization enhanced charge transfer: dual-band GaN-based plasmonic photodetector. Sci. Rep. 7, 1-8 (2017). https://doi.org/10.1038/srep40483

56. S. Abdalla, F. Marzouki, S. Al-Ameer, S. Turkestani, Electric properties of n-GaN: effect of different contacts on the electronic conduction. Int. J. Phys. 1, 41-48 (2013). https://doi. org/10.12691/ijp-1-2-3

57. C.D. Gelatt, H. Ehrenreich, Charge transfer in alloys: AgAu. Phys. Rev. B 10, 398 (1974). https://doi.org/10.1103/PhysR evB. 10.398

58. J.A. Rothschild, M. Eizenberg, Work function calculation of solid solution alloys using the image force model. Phys. Rev. B-Condens. Matter Mater. Phys. 81, 1-8 (2010). https://doi. org/10.1103/PhysRevB.81.224201

59. S.C. Fain, J.M. McDavid, Work-function variation with alloy composition: Ag-Au. Phys. Rev. B 9, 5099-5107 (1974). https ://doi.org/10.1103/PhysRevB.9.5099 